\title{
Adolescent Idiopathic Scoliosis
}

A Deformity in Three Dimensions

\author{
Ludvig Vavruch
}

\author{
Division of Orthopaedic Surgery \\ Department of Clinical and Experimental Surgery \\ Centre for Medical Image Science and Visualization \\ Faculty of Health Sciences \\ Linköping University \\ Sweden
}

Linköping 2018

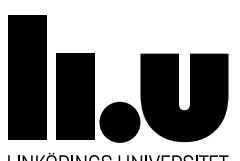




\section{Supervisor}

Hans Tropp, MD, PhD, Professor

Department of Clinical and Experimental Medicine, Linköping University, Linköping

\section{Co-supervisors}

Daniel Forsberg, PhD

Sectra AB, Linköping

Centre for Medical Image Science and Visualization, Linköping University, Linköping

Nils Dahlström, MD, PhD, Associate Professor

Department of Medical and Health Sciences, Linköping University, Linköping

Staffan Wirell, MD, PhD, Associate Professor

Department of Medical and Health Sciences, Linköping University, Linköping

\section{Faculty opponent}

Paul Gerdhem, MD, PhD, Associate Professor

Department of Clinical Science, Intervention and Technology, Karolinska Institutet, Stockholm

\section{Examination board}

Torbjörn Ledin, MD, PhD, Professor

Department of Clinical and Experimental Medicine, Linköping University, Linköping

Li Felländer-Tsai, MD, PhD, Professor

Department of Clinical Science, Intervention and Technology, Karolinska Institutet, Stockholm

Richard Levi, MD, PhD, Professor

Department of Medical and Health Sciences, Linköping University, Linköping

C) Ludvig Vavruch 2018

Layout: Camilla Vavruch

Language checking: Lorna O’Brien

Papers I-III reprinted with permission

Printed by LIU-Tryck, Linköping 2018

ISBN 978-91-7685-236-1

ISSN 0345-0082 
'Sooner or later, everything old is new again' Stephen King, The Colorado Kid 



\section{Abstract}

Scoliosis is a complex three-dimensional deformity of the spine. Even though it has been known for centuries, treatment of the deformity has focused on correcting only in the frontal plane. In the last decades, the need for three-dimensional assessment regarding scoliosis has been highlighted to better understand the cause and the principles of treating scoliosis. The overall aim of this dissertation is to provide knowledge to assess scoliosis as a three-dimensional problem.

The severity of scoliosis is measured with the Cobb angle from standing radiographs. Computed tomography (CT) examinations are used throughout this thesis. The first paper investigates the difference in Cobb angle measured from standing radiographs and supine CT examinations. The standing radiographs had larger Cobb angles with a mean difference of $11^{\circ}$ and a linear correlation between the two examinations from 128 consecutive patients with adolescent idiopathic scoliosis (AIS) planned for surgery.

The second paper compares the axial shape of vertebrae in 20 patients with AIS with a reference group. Clear asymmetry was observed in all vertebrae - superior and inferior end vertebrae as well as the apical vertebra - compared with corresponding vertebrae among the reference group. The asymmetry was most pronounced in the apical vertebra. A novel parameter, frontal vertebral body rotation (FVBR), was introduced to describe the internal rotation of the vertebrae in the axial plane.

Pelvic incidence (PI) is a measurement of the position of the sacrum in relation to the femoral heads. This is relevant in scoliosis because PI determines the pelvic configuration acting as a foundation to the spine. PI has traditionally been measured from standing radiographs. The third study investigates PI three-dimensionally, based on low-dose CT examinations, in 37 patients with Lenke type 1 or 5 curves compared with a reference group. A significantly higher PI was observed in patients with Lenke type 5 curves compared with the reference group and patients with Lenke type 1 curves.

Severe AIS is treated with corrective surgery. Two approaches are available: the predominant posterior approach and the anterior approach. In the fourth paper, these two approaches are evaluated with regard to three-dimensional correction, how well the correction is maintained over a 2-year follow-up and patient-reported outcome measures. Twenty-seven patients treated with the posterior approach and 26 patients treated with the anterior approach, all with Lenke type 1 curves, were included. Fewer vertebrae were fused in the anterior group, but the posterior group had a better correction of the deformity in the frontal plane. No difference was observed regarding three-dimensional correction and patient-reported outcome measures.

AIS is truly a complex three-dimensional deformity. More research is needed to fully comprehend the complexity of the scoliotic spine. 


\section{Populärvetenskaplig sammanfattning på svenska}

\section{Adolescent idiopatisk skolios - den tredimensionella deformiteten}

Skolios är en deformitet som påverkar ryggen tredimensionellt, i frontal-, sido- och axialplanet. Trots att detta beskrivits redan 1865 av William Adams har deformiteten i första hand utretts och behandlats avseende storleken på kröken i frontalplanet. Sedan mitten av 80-talet har behovet av tredimensionell bedömning påtalats allt mer.

Den vanligaste typen av skolios drabbar ungdomar över 10 års ålder och då oftare flickor. Orsaken är okänd (idiopatisk), varför den benämns adolescent idiopatisk.

Traditionellt har skolios bedömts med hjälp av mätning av krökens storlek i frontalplanet (Cobbvinkeln), baserat på stående slätröntgenundersökning. Denna undersökning avbildar deformiteten tvådimensionellt. Tredimensionella rekonstruktioner går att skapa genom datortomografiska (DT) undersökningar som utförs i liggande, enligt ett lågdosprotokoll vilket minimerar strålningen. Stående och liggande undersökningar belastar ryggen olika och ger därför olika storlek på kröken. Den första studien undersöker sambandet mellan krökens storlek mätt enligt Cobb vid stående respektive liggande undersökning. Det föreligger ett linjärt samband mellan de båda undersökningarna och Cobbvinkeln i liggande är $11^{\circ}$ mindre än i stående.

Den andra studien undersöker hur kotkropparna har deformerats hos patienter med operationskrävande adolescent idiopatisk skolios. Kotorna hos skoliospatienter jämförs med motsvarande kotor hos en ålders- och könsmatchad kontrollgrupp. Resultatet visar att kotorna är deformerade vid skolios, med den tydligaste deformationen i krökens apex. En ny parameter, "Frontal Vertebral Body Asymmetry" (FVBR), införs som mått på den interna rotation som ses i kotorna i axialplanet vid idiopatisk skolios.

Bäckenet utgör basen för ryggraden. Pelvic incidence är ett mått på bäckenets konfiguration, och mäts traditionellt med slätröntgen där såväl korsryggen som båda höftkulorna finns avbildade. Den tredje studien undersöker pelvic incidence med hjälp av tredimensionella rekonstruktioner från DT. Studien visar att krökar av Lenke typ 5 (primärt lumbala) har högre pelvic incidence jämfört med referensgruppen och krökar av Lenke typ 1 (primärt thorakala).

Patienter med grav skolios, med Cobbvinkel över $45-50^{\circ}$, behandlas kirurgiskt. Det finns idag huvudsakligen två alternativa operationsmetoder: en med bakre och en med främre teknik. Den bakre metoden är den mest använda. Kunskapen om vilken korrektion som åstadkommes med respektive metod är dock ofullständig. Detta undersöks i fjärde delarbetet. Fyrtio patienter opererade med respektive metod jämförs avseende tredimensionell korrektion. Patienterna följs upp under en tvåårsperiod för att undersöka hur väl korrektionen bibehålls. Livskvalitet samt funktionsnivå bedöms med hjälp av två olika frågeformulär. Vi fann att antalet stelopererade kotor är färre i den främre gruppen, medan graden av korrektion i frontalplanet är större i den bakre gruppen. Ingen säker skillnad observerades mellan grupperna varken avseende tredimensionell korrektion eller patientrapporterad livskvalitet. 


\section{List of Papers}

I Vavruch L, Tropp H. A comparison of Cobb angle: standing versus supine images in late-onset idiopathic scoliosis. Pol J Radiol 2016;81:270-276. doi: 10.12659/ PJR.895949

II Vavruch L, Forsberg D, Dahlström N, Tropp H. Vertebral axial asymmetry in adolescent idiopathic scoliosis. Spine Deform 2018;6:112-120.e1. doi: 10.1016/ j.jspd.2017.09.001

III

Brink RC, Vavruch L, Schlösser TPC, Abul-Kasim K, Ohlin A, Tropp H, Castelein RM, Vrtovec T. Three-dimensional pelvic incidence is much higher in (thoraco)lumbar scoliosis than in thoracic scoliosis and controls. Eur Spine J 2018; doi: 10.1007/s00586-018-5718-6. [Epub ahead of print]

IV

Vavruch L, Brink RC, Malmqvist M, Schlösser TPC, van Stralen M, Abul-Kasim K, Ohlin A, Castelein RM, Tropp H. Surgical outcomes of anterior versus posterior fusion in Lenke type 1 late-onset idiopathic scoliosis. Submitted 


\section{Contents}

$\begin{array}{ll}\text { Abstract } & 1\end{array}$

Populärvetenskaplig sammanfattning på svenska 3

Adolescent idiopatisk skolios - den tredimensionella deformiteten 3

List of Papers $\quad 5$

$\begin{array}{ll}\text { Contents } & 7\end{array}$

List of Abbreviations $\quad 9$

$\begin{array}{ll}\text { Introduction } & 11\end{array}$

$\begin{array}{ll}\text { Scoliosis } & 13\end{array}$

Non-idiopathic scoliosis $\quad 13$

$\begin{array}{ll}\text { Idiopathic scoliosis } & 13\end{array}$

$\begin{array}{ll}\text { Anatomy and biomechanics } & 15\end{array}$

The normal spine $\quad 15$

$\begin{array}{ll}\text { The scoliotic spine } & 15\end{array}$

Radiology 17

Radiation hazards $\quad 17$

Radiographs $\quad 17$

EOS 19

Computed tomography $\quad 19$

Magnetic resonance imaging 20

$\begin{array}{ll}\text { Ultrasonography } & 20\end{array}$

Diagnostic measurements $\quad 21$

$\begin{array}{ll}\text { Cobb angle } & 21\end{array}$

$\begin{array}{ll}\text { Vertebral rotation } & 22\end{array}$

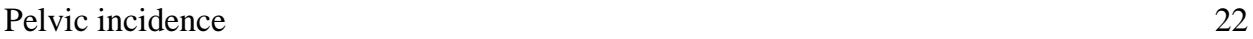

Classification of idiopathic scoliosis $\quad 24$

$\begin{array}{ll}\text { King classification } & 24\end{array}$

$\begin{array}{ll}\text { The Lenke classification } & 24\end{array}$

Corrective surgical approaches $\quad 29$

$\begin{array}{lr}\text { Posterior approach } & 29\end{array}$

Anterior approach $\quad 30$

$\begin{array}{ll}\text { Selective fusion } & 31\end{array}$ 
Questionnaires

SRS-22

EQ5D 3L

Aims

Patients

Methods

Ethical approval

Results

Strengths and limitations

Discussion $\quad \mathbf{5 1}$

Positioning of the patient at radiologic evaluation $\quad 51$

Vertebral asymmetry in the axial plane $\quad 51$

Pelvic incidence $\quad 53$

$\begin{array}{ll}\text { Corrective surgery } & 54\end{array}$

$\begin{array}{ll}\text { Conclusions } & 57\end{array}$

$\begin{array}{ll}\text { Future research } & 59\end{array}$

$\begin{array}{ll}\text { Acknowledgments } & 61\end{array}$

$\begin{array}{ll}\text { References } & 63\end{array}$

$\begin{array}{ll}\text { Papers } & 79\end{array}$ 


\section{List of Abbreviations}

2D

3D

AIS

AVBA

AVR

CI

CSVL

CT

EQ5D 3L

FVBR

LOIS

MRI

PI

SD

SRS-22 two-dimensional

three-dimensional

adolescent idiopathic scoliosis

axial vertebral body asymmetry

axial vertebral rotation

confidence interval

center sacral vertical line

computed tomography

EuroQol 5 Dimensions 3 Levels Questionnaire

frontal vertebral body rotation

late-onset idiopathic scoliosis

magnetic resonance imaging

pelvic incidence

standard deviation

Scoliosis Research Society-22 Questionnaire 


\section{Introduction}

Scoliosis is a deformity affecting the spine in all three planes. In the frontal plane, there are lateral curves with vertebrae deviating from the midline. A relative anterior overgrowth of the vertebral bodies changes the sagittal alignment of the spine, resulting in a hypokyphosis and/or hyper-lordosis. Each vertebra within the deformity is not just laterally deviated and tilted, it is also rotated in the axial plane. This means that the scoliotic spine is deformed in all three planes. The three-dimensional (3D) nature of the deformity has been known for a long time. William Adams described the complexity of the scoliotic spine in 1865 based on dissection of cadavers with idiopathic scoliosis (1). The rotation of the vertebral bodies away from the midline toward the convexity of the curvature in adolescent idiopathic scoliosis (AIS), was described by Somerville (2) and Roaf (3).

Even though the spine is deformed in all three dimensions, the evaluation of scoliosis has, historically, been based on two-dimensional (2D) frontal and lateral radiographic examinations. The gold standard for describing scoliosis is the Cobb angle (4). Right lateral deviation and axial vertebral rotation (AVR) are to some degree physiologic in the mid and lower part of the thoracic spine in adolescence and beyond $(5,6)$. It has been hypothesized that this is due to the location of the heart in the chest (7). A frontal Cobb angle of $10^{\circ}$ or more is defined as scoliosis according to the Scoliosis Research Society (8).

Because of the limited information regarding the complexity of the deformation as obtained by $2 \mathrm{D}$ images, the need for 3D assessment and diagnostics has been highlighted $(9,10)$. Threedimensional images and reconstructions have been made available through the development of new technologies such as biplanar radiographs, computed tomography (CT) and magnetic resonance imaging (MRI) $(11,12)$.

These new technologies increase the understanding of the complex scoliotic spine. However, they also require that the methods and classifications developed for the $2 \mathrm{D}$ assessment of scoliosis are changed and adapted into a 3D context.

The overall aim of this dissertation is to provide some answers for the adaptation of a more 3D assessment of scoliosis. 


\section{Scoliosis}

Scoliosis is categorized regarding the underlying cause of the deformity. Scoliosis with a known cause is categorized as non-idiopathic scoliosis, whereas curves of unknown cause is called idiopathic scoliosis.

\section{Non-idiopathic scoliosis}

Congenital scoliosis is caused by distorted formation and segmentation of the vertebrae (13). The deformity is the result of "normal loads acting upon an abnormal spine".

Neuromuscular scoliosis is associated with neurologic deficits, muscular problems, or different syndromes with dysfunctional nervous control (14). The deformity is the result of "abnormal loads acting upon a normal spine".

Adult degenerative scoliosis, is a consequence of altered biomechanics due to degeneration in the adult spine with a previous idiopathic scoliosis or an asymmetric degeneration of the disc and facet joint and a "de novo" deformity (15).

In all cases except idiopathic scoliosis, a basis for the development of the deformity is known. Despite this, the mechanism for the progression of the deformity is still unknown, no matter the underlying cause.

\section{Idiopathic scoliosis}

There are two predominant ways to classify idiopathic scoliosis based on the age when the deformity is diagnosed. The first system differentiates between infantile (diagnosed from birth to 3 years of age), juvenile (diagnosed after 4 years of age but before 10 years), and adolescent (diagnosed after the age of 10 years) scoliosis (16). The second system distinguishes only between early-onset and late-onset scoliosis, where early-onset is diagnosed before and lateonset diagnosed after the age of 10 years (17). This thesis focuses solely on adolescent idiopathic scoliosis/late-onset idiopathic scoliosis, which are considered synonymous throughout this thesis.

Idiopathic scoliosis is the most common form of scoliosis (18-20). The prevalence of idiopathic scoliosis ranges from $0.5 \%$ to $5.2 \%$ in different populations $(18,21,22)$. Both the prevalence and the severity of the deformity are higher in females than males. Weinstein et al. found that the female to male ratio was higher with increasing Cobb angle - approximately 2:1 in deformities with a Cobb angle above $10^{\circ}$ and 10:1 in curvatures with a Cobb angle above $30^{\circ}$ (19).

As the name implies, the cause of idiopathic scoliosis is unknown, but it is most certainly multifactorial, including genetics, heritage, biomechanical aspects, as well as hormonal factors (23). For some reason, "abnormal" loads act upon an otherwise "normal" spine. 


\section{Anatomy and biomechanics}

\section{The normal spine}

The normal spine consists of 7 cervical, 12 thoracic, and 5 lumbar vertebrae. Caudally, the foundation of the spine consists of fused sacral vertebrae connecting the spine to the pelvis via the sacro-iliac joints. In the frontal plane, the spine is almost straight, but a small right convexity and vertebral rotation are usually seen in the thoracic spine at the level of the heart $(5,6)$.

There are three curvatures in the sagittal view: a lordosis in the cervical and the lumbar regions, and a kyphosis in the thoracic spine. The sagittal alignment found in Homo sapiens enables the upright position. However, this results in a relative instability in the spine, especially, in the thoracolumbar region (24-26).

Intervertebral discs separate vertebrae bodies, providing damping and flexibility. A motion segment in the spine includes two vertebrae separated by one intervertebral disc. Posteriorly, two joints consisting of the inferior facet of the upper vertebra and the superior facet of the lower vertebra link the segment like a chain. It is the constitution of the facet joints that limits the mobility of the segment. High mobility is seen in the cervical and lumbar spine, whereas the mobility in the thoracic spine is limited (27). This is mainly because the ribcage is connected to the thoracic spine via costo-vertebral and costo-transversal joints. The ribcage is usually symmetrical in humans without scoliosis.

Different ligaments connect the vertebrae, contributing to the stability of the vertebral column. An anterior longitudinal ligament extends along the anterior part of the spine, and a posterior longitudinal ligament connects the vertebral bodies posteriorly in the ventral aspect of the spinal canal. Posterior to the spinal canal, the ligamentum flavum and interspinous and supraspinous ligaments connect laminae and the spinous processes, respectively.

\section{The scoliotic spine}

In idiopathic scoliosis, the number and segmentation of the vertebrae are the same as in the normal spine. However, the column is no longer straight in the frontal plane. Instead, there are lateral curves, typically right convex in the thoracic region and left convex in the thoracolumbar and lumbar region. The major curve, also called the primary curve, is the origin of the deformity and is always considered structural by definition according to the Lenke classification (28). Secondary curves arise as compensation for the imbalance caused by the primary curve. The primary curve is always more rigid than the compensatory curve(s). The most lateral point of the curve from a central line is called the curve's apex and may either be a single vertebra or the disc between two vertebrae.

The sagittal alignment is altered by a relative elongation of the anterior part of the spine compared with the posterior part (29-31). This results in either hypokyphosis or even local lordosis in the thoracic spine and hyper-lordosis in the lumbar spine. The role of sagittal 
alignment and the relative instability it causes in the human spine has been hypothesized in several studies to be a decisive reason for the emergence of scoliosis $(24,32)$.

Both vertebrae and intervertebral discs are deformed in the scoliotic spine. Schlösser et al. (33) and Little et al. (34) reported a higher degree of deformation in the intervertebral discs compared with vertebrae. In the sagittal plane, the anterior aspects of the vertebrae are more prominent than in the normal spine. In the axial plane, vertebrae are deformed and asymmetric. The vertebrae are rotated as a whole, but there is also an internal rotation of the vertebral body. Kotwicki et al. described that both the spinous process and the vertebra are rotated toward the convexity (35).

On inspection, patients with scoliosis typically have an imbalance in the height of their shoulders. When bending forward, a thoracic hump appears on the convex side of the thorax. This is the result of ribcage deformation and rotation over time because of vertebral rotation. Adams' forward-bend test is used to evaluate the truncal rotation. A scoliometer is a tool for measuring this rotation, and the method is used in many countries for screening schoolchildren for scoliosis (36-38).

The deformity increases as the patient grows and the highest progression is seen during growth spurt (19). The risk of deformity progression is greater the younger the patient is at onset. Curve progression is most probable in young skeletally immature girls with large curves over $30^{\circ}(19)$.

The effects of the deformity are most prominent in the apical region of the curvature. The lateral deviation and rotation of the curve, as well as the asymmetry and deformity of each vertebra, is most pronounced at this level. 


\section{Radiology}

Different methods are used in the evaluation of scoliosis. Among these are different types of conventional radiographs, CT, MRI, and ultrasonography. A description of the advantages and disadvantages of each method follows.

\section{Radiation hazards}

Patients with scoliosis will be examined multiple times with different types of radiologic procedures. Simony et al. reported a mean of 16 radiologic examinations (range 834) for their group of patients from the beginning of the treatment until 2 years after definitive treatment (39). Several side effects of the increased accumulated radiation have been reported, including infertility and increased risk for malignancies such as breast cancer and thyroid cancer (39-44). It has been estimated that an increase of radiation by $1 \mathrm{~Sv}$ increases the overall risk coefficient of developing a fatal cancer by 5\% (45). Due to the increased levels of radiation, it is crucial to minimize the number of examinations exposing the patients to radiation. One important method to reduce the radiation level is to use posterior-anterior radiographs instead of anterior-posterior views. This reduces the radiation exposure of the breast and thyroid, which reduces the risk of developing malignancy $(44,46)$. Geijer et al. described several methods to optimize and reduce the radiation from radiologic examinations in patients with scoliosis (47, 48). An overall reduction in the number of examinations that include ionizing radiation, performing these only when necessary as well as using alternative non-ionizing diagnostic methods, are other important ways to reduce the risk of inducing malignancy. Further development of both hardware and software will hopefully continue reduction of radiation exposure to patients with scoliosis.

\section{Radiographs}

Traditionally, scoliosis has been evaluated using frontal and sagittal examinations from standing radiographs (Figure 1). The images are 2D and provide a good overview of the deformity as well as an opportunity to follow curve progression over time. The radiation dose for a routine examination is approximately $0.1 \mathrm{mSv}$. To assess the flexibility of the deformity, bending examinations - either standing and bending laterally or over a fulcrum - are performed (49). Assessment of the curve's flexibility is important in classification of the deformity. This is further explained in the section on 'Classification of idiopathic scoliosis'. 


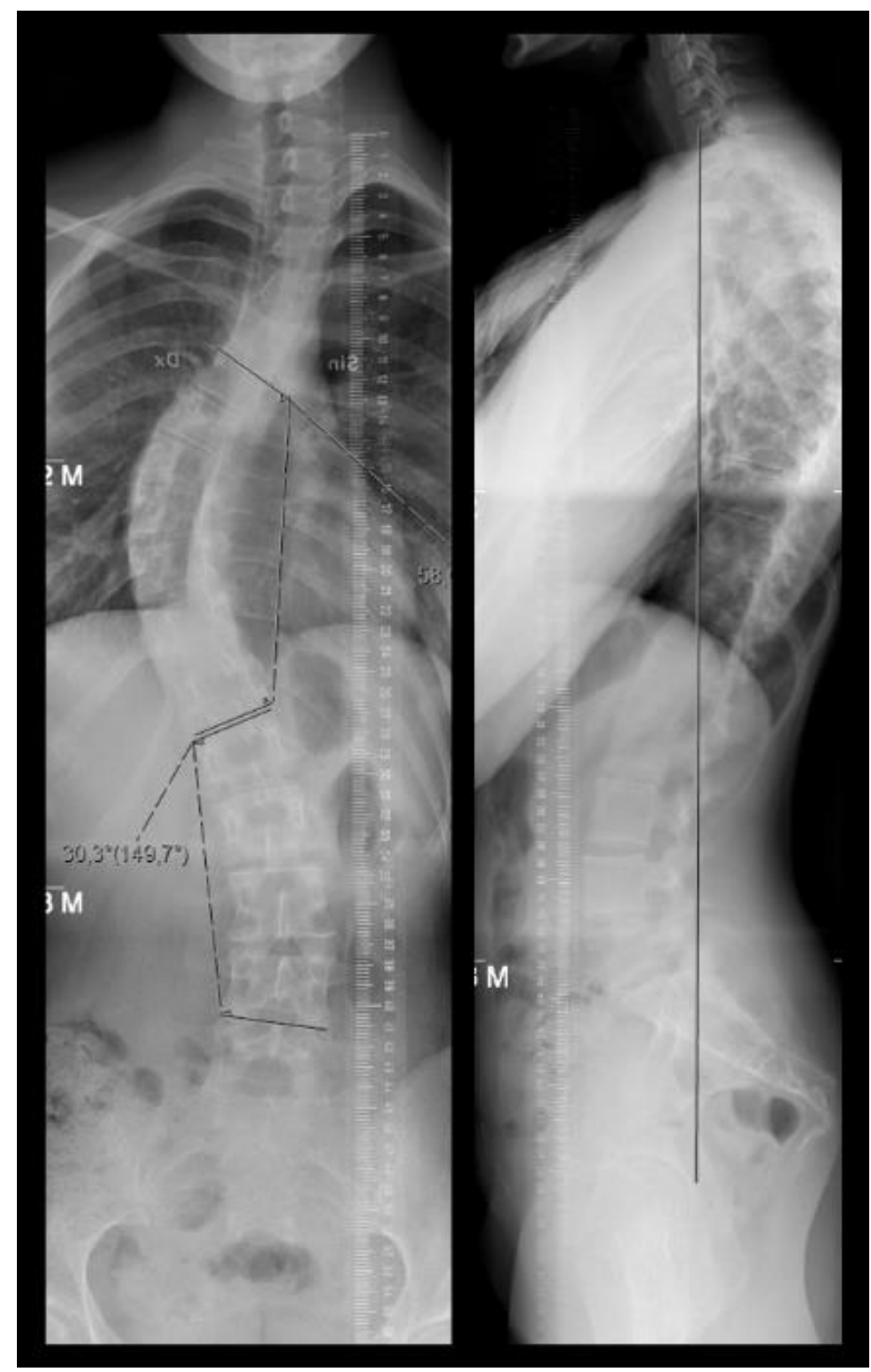

Figure 1. Whole-spine images obtained by standing radiographs. Frontal plane (left) and sagittal plane (right). 


\section{EOS}

EOS is a system consisting of biplanar radiographs (EOS Imaging, Paris). Examinations are performed in a standing position (50). The two examinations are merged, providing a 3D reconstruction of the spine. No true reconstruction is obtained, because the reconstruction approximates a model. Advantages of the system are that it provides axially loaded images (standing) with great possibilities for curve assessment and pelvic incidence (PI) measurements at very low radiation doses $(12,51,52)$. The main disadvantages are that the equipment is expensive and that no true reconstructions are obtained. This reduces the possibility of performing detailed assessments of the skeletal structures (e.g., in malformations).

\section{Computed tomography}

CT is ideal for a detailed assessment of skeletal structures (Figure 2). Standing CT examinations have been available for several years but are not widely used in Sweden. The typical CT examination is performed in supine position, which affects the spine because of the reduced/altered gravitational load in the craniocaudal direction. This is the reason why CT examinations are not directly comparable with those from standing radiographs. Another disadvantage is the ionizing radiation associated with CT. Consequently, special low-dose protocols for assessment of skeletal structures have been developed $(11,53)$. Using such a protocol, whole-spine examinations with radiation doses as low as 0.3-0.4 $\mathrm{mSv}$ are achievable (53). The low-dose CT protocol is part of pre- and postoperative follow-up at the orthopedic departments in both Linköping and Malmö.

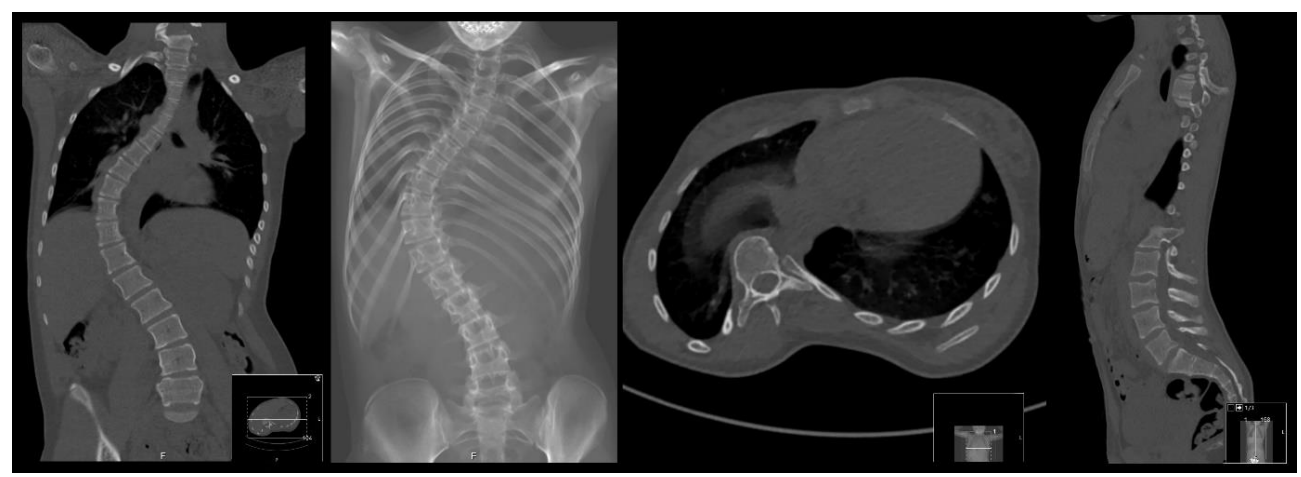

Figure 2. Images from a low-dose CT examination for detailed skeletal assessment. Frontal plane (left), 3D reconstruction (middle left), axial plane (middle right) and sagittal plane (right). 


\section{Magnetic resonance imaging}

MRI is best suited for examination of soft tissue, such as nerve structures, discs and muscles (Figure 3). MRI is also performed in the supine position. No ionizing radiation is used because the method is based on magnetic resonance. Whole-spine MRI examinations are performed as routine in the pre-operative care of patients with scoliosis at the orthopedic departments in both Linköping and Malmö. The aim is to rule out anomalies in the nervous system and spinal canal such as Chiari malformation, syrinx, tethered cord, or intra-spinal processes that could explain the deformity (54-57). Time-consuming examinations and the need for patients to be motionless during the examination, sometimes requiring general anesthesia, are disadvantages with this method.

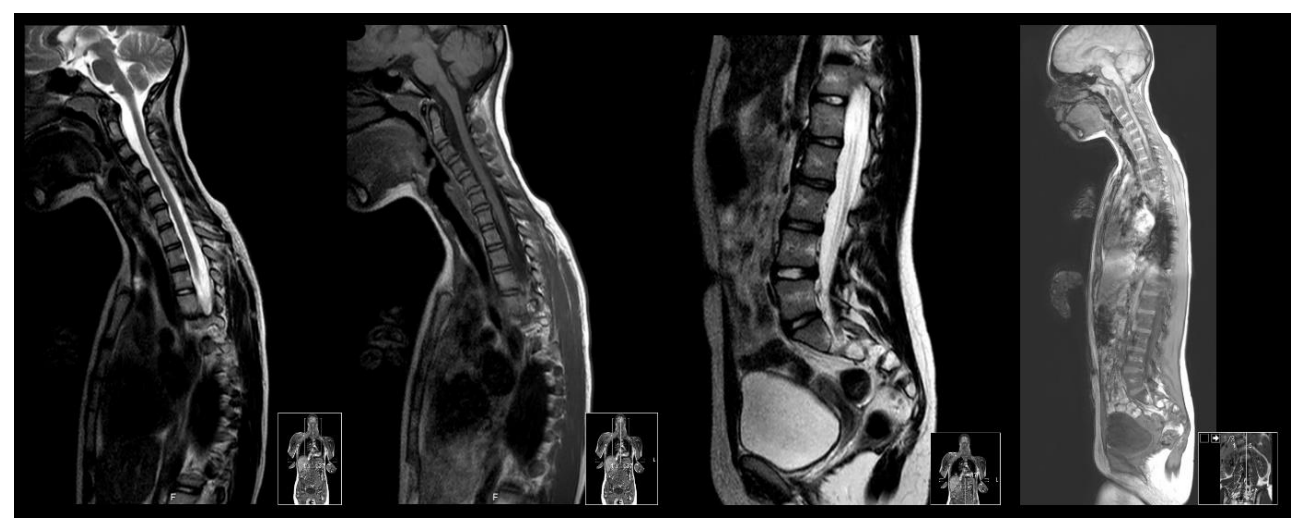

Figure 3. Whole-spine MRI examination for assessment of nerve structures.

\section{Ultrasonography}

Ultrasonography is a relatively new method to assess spinal deformity (58). It can be performed in a standing position, and the patients are not exposed to any ionozing radiation. Angles are calculated based either on measurements of spinal processes or transverse processes (58-60). Brink et al. showed that the curve angles are smaller when measured with ultrasound compared with the Cobb angle on radiographs, but there is excellent correlation between the measurements (60). The technique is promising but still under evaluation and not yet commonly used in everyday practice in Sweden. 


\section{Diagnostic measurements}

\section{Cobb angle}

The Cobb angle was first described by John Robert Cobb in 1948 (4). The measurement is defined as the angle between the upper end plate of the most cephalic vertebra and the lower end plate of the most caudal vertebra in the curvature in the frontal plane (Figure 4). The standard measurements are performed on standing radiographs considered the gold standard for evaluating the severity of a spinal deformity. Repeated measurements reveal up to $5^{\circ}$ measurement error, hence a clinically significant difference between two examinations is considered if the difference is larger than $5^{\circ}$ (61-63). The flexibility of the curves, as seen in Figure 4, is evaluated with measurements of the Cobb angle in bending examinations (28). Assessment of the Cobb angle is an easy way to follow the progress of the deformity. However, despite being considered the gold standard for evaluation of scoliosis, the Cobb angle provides very limited information regarding the $3 \mathrm{D}$ properties of the spinal curvatures.

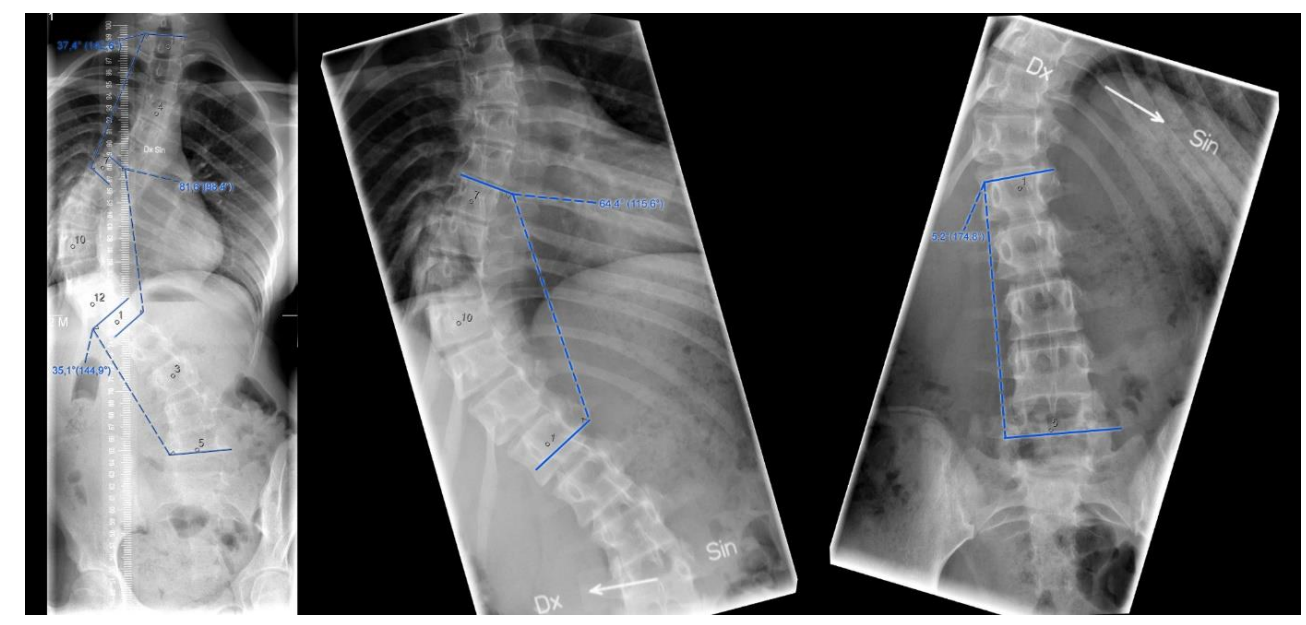

Figure 4. The Cobb angle measurements on images from standing radiographs (left). Bending examinations (middle and right) reveal the flexibility of the primary and compensatory secondary curve.

The Cobb angle is dependent on the axial loads acting on the spine. In a standing position, gravity is affecting the deformity maximally, resulting in a large Cobb angle. Gravity affects the magnitude of the deformity to a lesser degree and in a different direction in a supine position, with a smaller Cobb angle as a consequence. This implies that the posture of the patient alters the measurement of the Cobb angle, which needs to be considered when assessing examinations performed in the supine position, such as CT and MRI. The relationship between measurements of the Cobb angle from standing and supine examinations has been studied before (64-66). 
However, many of these studies lack information regarding both primary and secondary curves in both thoracic and thoracolumbar/lumbar areas, in both males and females. All of these aspects are covered in Paper I of this thesis.

\section{Vertebral rotation}

As mentioned in the section on Anatomy and biomechanics, the vertebral rotation is a considerable part of the scoliotic deformity. A variety of methods have been described using different modalities to evaluate vertebral rotation (67). Historically, vertebral rotation has been assessed on 2D examinations from radiographs, assessing the visibility of the spinous process (the Cobb method (4)) or the pedicles (the Nash-Moe method (68) or the Peridriolle method (69)). The accuracy of these methods is questionable because they depend heavily on the quality of the examinations. Aaro and Dahlborn and later Ho et al. introduced a method for measurement of vertebral rotation based on CT examinations $(70,71)$. Methods for assessment based on MRI have also been developed, as well as computerized methods for various degrees of automated calculations $(72,73)$. A yet unsolved problem regarding vertebral rotation is the reference point with which it is compared. So far, no ideal reference point has been found, either internally in the body or externally.

There is a lack of knowledge regarding detailed analysis of vertebral rotation and asymmetry in the axial plane. This gap was the reason for Paper II.

\section{Pelvic incidence}

Idiopathic scoliosis develops and progresses due to a multitude of factors. Several studies have highlighted the crucial role of the sagittal shape of the spine and the biomechanics of the upright human spine $(30,32,74-78)$.

The pelvic sacral angle was described by During et al. in 1985. This definition was later expanded by Duval-Beaupère et al. to the term pelvic incidence. This parameter was defined as the relationship between the pelvic anatomy and spinal alignment $(75,76)$.

PI is assessed from standing radiographs, including the sacrum and both femoral heads. PI is the angle between a line perpendicular to the sacral end plate and a line connecting the center of the femoral head and the center of the sacral plateau. The sacral slope (i.e., the angle between the upper end plate of the sacrum and a horizontal line) plus the pelvic tilt (the angle between the vertical reference line and the line connecting the midpoint of the sacral plateau to the center of the femoral heads) equals the PI (Figure 5). The development of the PI is continuous and increasing until late adolescence. The PI then remains constant for the rest of the person's life, i.e., after the natural growth phase of the body is completed. Age and positioning do not affect this development curve (77-79).

$\mathrm{PI}$ is regarded as essential in providing information for 3D assessment of the spine. However, measurements have continued to be performed on 2D standing radiographs. This results in only partial opportunities for true 3D reconstructions $(80,81)$. There have been innovative studies 
of pelvic parameters using 3D reconstructed radiographs by Pasha et al. as well as by Vrtovec et al., who used CT scans to measure the 3D PI in a population of non-scoliotic individuals, and this method was shown to have higher accuracy than customary measurements on ordinary sagittal X-rays $(80,82)$.

As far as can be ascertained, no study has been done using accurate $3 \mathrm{D}$ reconstruction to evaluate the PI in patients with AIS. This was addressed in Paper III of this thesis.

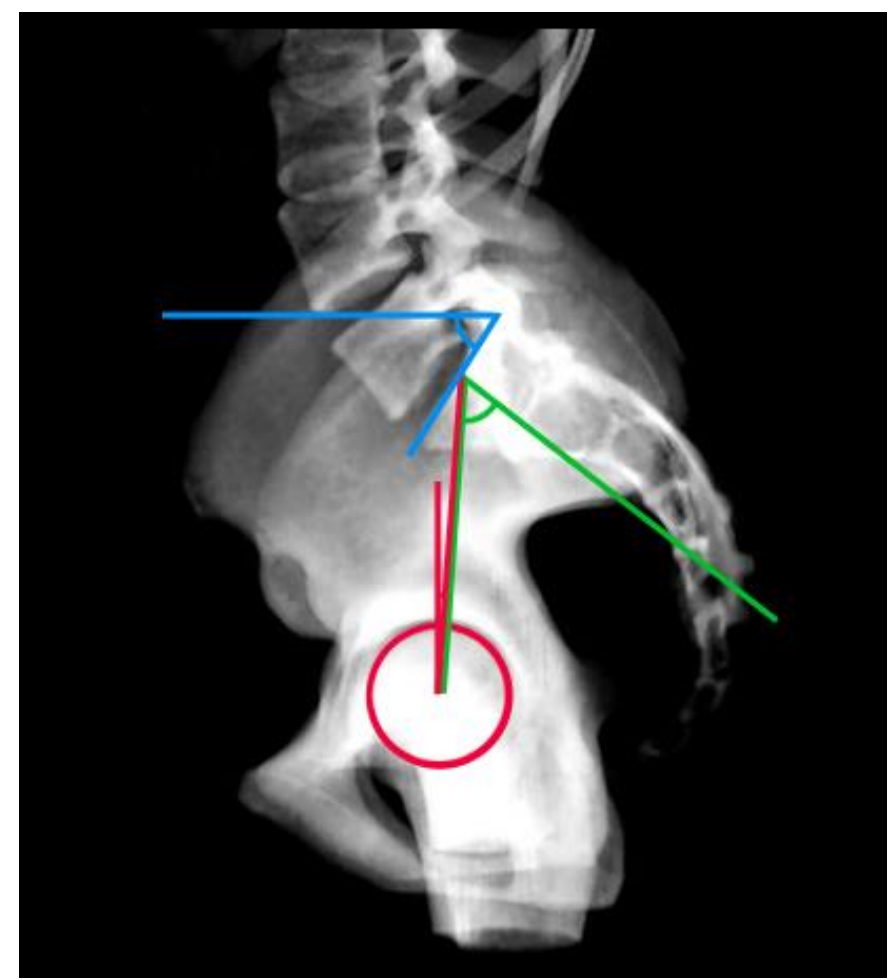

Figure 5. A schematic picture of pelvic incidence. The sacral slope (blue angle $)+$ the pelvic tilt (red angle $)=$ pelvic incidence $($ green angle $)$. 


\section{Classification of idiopathic scoliosis}

Different classification schemes for idiopathic scoliosis exists. The classification used throughout this thesis is the Lenke classification. However, the first classification used was the King classification.

\section{King classification}

In 1983, King et al introduced a classification of idiopathic scoliosis (79). Curves were divided into five categories based on localization and flexibility of the curve: main lumbar curves (type I), main thoracic curves (types II-IV), and double thoracic curves (type V). The classification not only described the deformities but also included recommendations for corrective surgery.

Several studies have evaluated the King classification raising concerns regarding inadequate reliability and reproducibility $(80,81)$.

\section{The Lenke classification}

Due to relatively poor interobserver reliability of the King classification, the Lenke classification was introduced in 2001. This classification is based on the localization of the curves in the frontal plane as well as the degree of kyphosis in the thoracic region in the sagittal plane (28).

The localization of the apical region determines the type of curve. It is defined as proximal thoracic if the apex is above Th2, thoracic if the apex is between Th2 and the disc between Th11-Th12, thoracolumbar between Th12 and L1, and lumbar below the disc L1-L2 to L4. The classification consists of six types (Figure 6). Types 1 to 4 originate from the thoracic spine and types 5 and 6 from the lumbar spine.

The biggest curve in the frontal plane is defined as the primary or major curve and is always considered structural. If secondary (compensatory) curves grow large enough, they will eventually become structural as well. They are defined as structural minor curves when their Cobb angle is $25^{\circ}$ or larger on bending examinations. In the sagittal plane, secondary curves are considered structural if they have a local kyphosis of $20^{\circ}$ or more (between Th2 and Th5 for proximal thoracic curves and between Th10 and L2 for main thoracic and thoracolumbar/lumbar curves) (Table 1).

Idiopathic curves are classified with lumbar modifier grades $\mathrm{A}-\mathrm{C}$, depending on how lateral the lumbar apical region is in relation to the center sacral vertical line (CSVL) in the frontal plane; A (between pedicles), B (touches the apical pedicle), and C (apical vertebral bodies completely lateral). CSVL also defines the stable vertebra, which is the first vertebra below the major curve bisected by the CSVL. 
Finally, the sagittal alignment between Th5 and Th12 is assessed in the Lenke classification; $<10^{\circ}(), 10-40^{\circ}(\mathrm{N})$, and $>40^{\circ}(+)$.

Lenke type 1 (primary thoracic curve) is the most common $(82,83)$. 


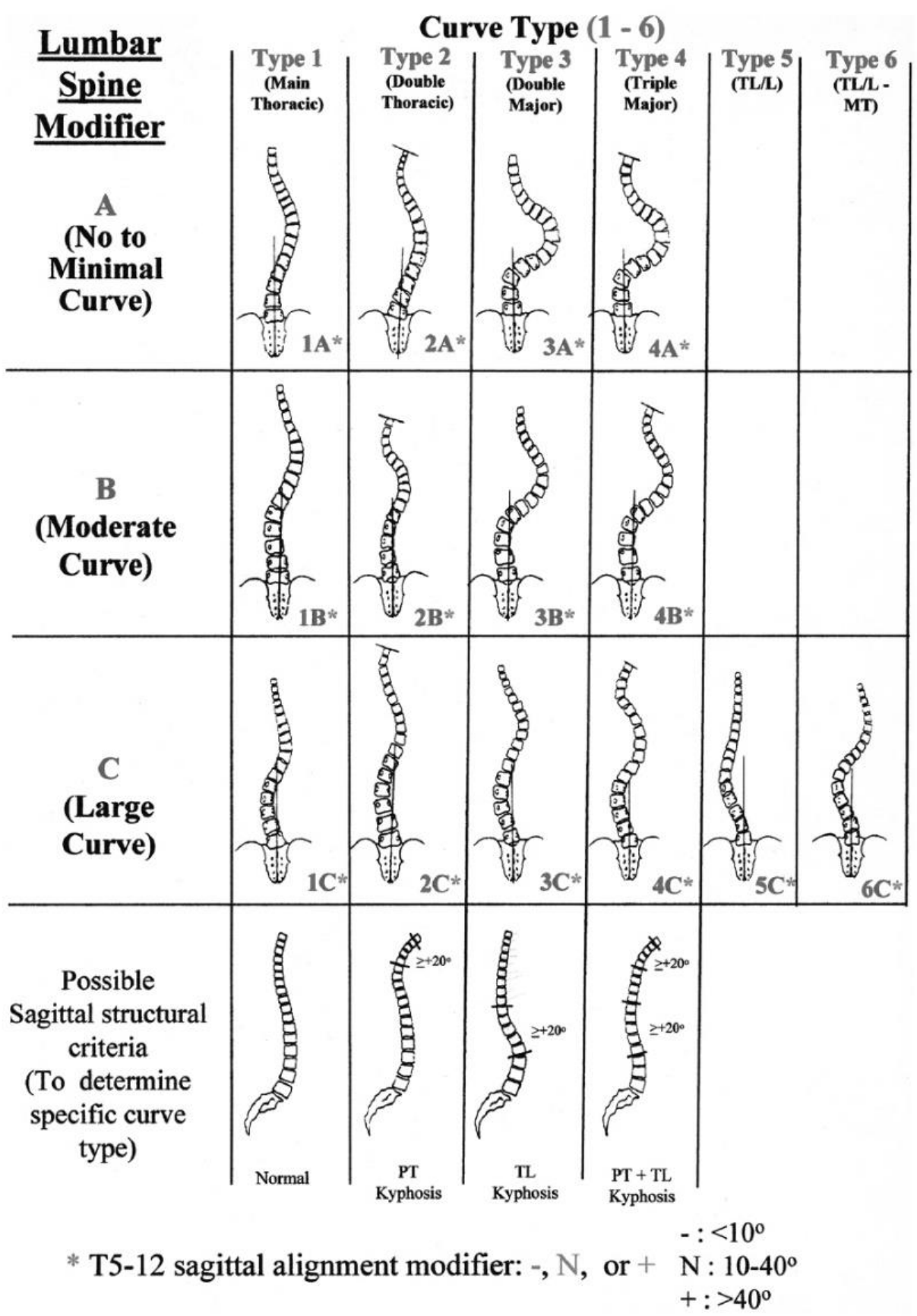

Figure 6. A schematic overview of the Lenke classification. Image reprinted with permission from reference 28 and https://journals.lww.com/jbjsjournal/pages/default.aspx. 


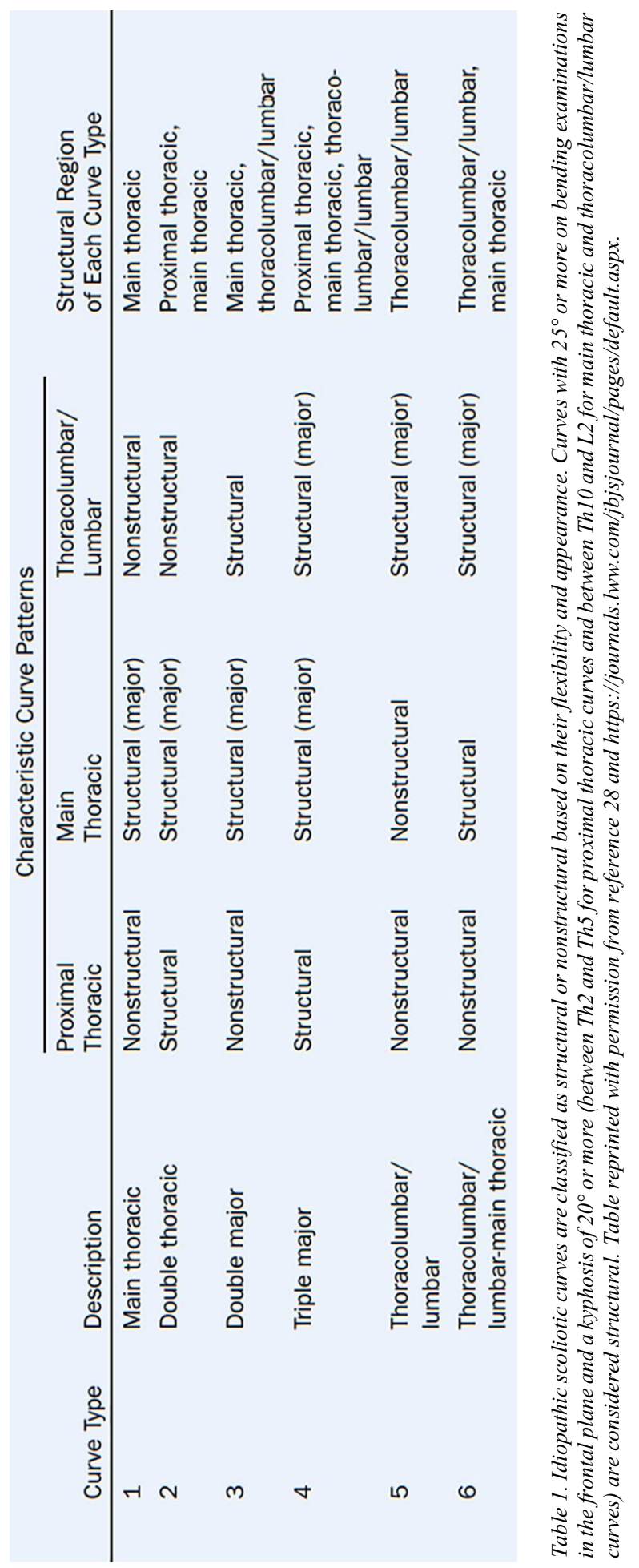




\section{Corrective surgical approaches}

The primary goal of corrective scoliosis surgery in adolescents is to halt curve progression and to prevent pain and pulmonary dysfunction $(20,77)$. Secondary goals of surgical correction are restoration of $3 \mathrm{D}$ spinal alignment as well as cosmesis.

As a patient with scoliosis grows, the spinal deformity worsens. Rapid curvature progression with Cobb angles around $45^{\circ}$ is considered an indication for surgery even for patients who are still growing. If the curve is large enough, it will continue to increase under its own load, even after the patient has stopped growing. The cut off level for this is approximately a Cobb angle of $45^{\circ}(84-86)$. Curves larger than $45^{\circ}-50^{\circ}$ that continue to increase after growth arrest are also an indication for surgery $(87,88)$.

There are other treatments that can be considered for treating scoliosis before surgery becomes an option, including different types of braces as well as physiotherapy (89-92). However, it is not within the scope of this thesis to describe these options further.

There are two main approaches for corrective surgery: an anterior or a posterior approach (9399). It remains unclear what 3D surgical outcomes are obtained using either of these surgical approaches. Theoretically, to restore physiologic thoracic kyphosis, the thoracic hypokyphosis in AIS can be treated by either anterior shortening or posterior lengthening of the spine.

\section{Posterior approach}

In 1955, Paul Herrington introduced a rod construct for curve correction in patients with scoliosis (93). The method was improved by Eduardo Luque with segmental fixation by sublaminar wires, which improved stability and correction (100). A dual rod construct fixed to the spine with hooks was introduced by Cotrel and Dubousset (95). Suk et al. introduced the use of pedicle screw fixation in the thoracic spine, making the all-screw construct possible, which is stronger and more stable than hybrid constructs with hooks and screws $(101,102)$. Since the introduction of pedicle screws, posterior instrumentation has been the predominant method for corrective scoliosis surgery (103-106).

The posterior approach can be used to treat all Lenke types of scoliosis (28). The patient is placed in the prone position and the access to the spinal column is fast and easy. An all pedicle screw construct is very strong and enables very powerful correction (Figure 7). Usually no release of the vertebral column is performed, but depending on the diameter and material of the instrumentation both, a frontal and a sagittal correction are possible (107). Correction can be obtained by compression-distraction, rod-derotation maneuvers, in situ contouring, en bloc or direct vertebral body derotation (108). These techniques can be applied individually or in combination.

One disadvantage of the posterior approach is that longer fixations are required to correct the same curvature, compared with the anterior method. This is because the fixation usually needs to cover the first stable vertebra, which typically is one or two levels below the level of the 
curve end vertebra (83). This often results in less mobility and range of motion in the lumbar spine of these patients. There are reports of higher infection rates using the posterior approach, but the frequency has declined since the introduction of rods made of titanium instead of stainless steel (109-111).

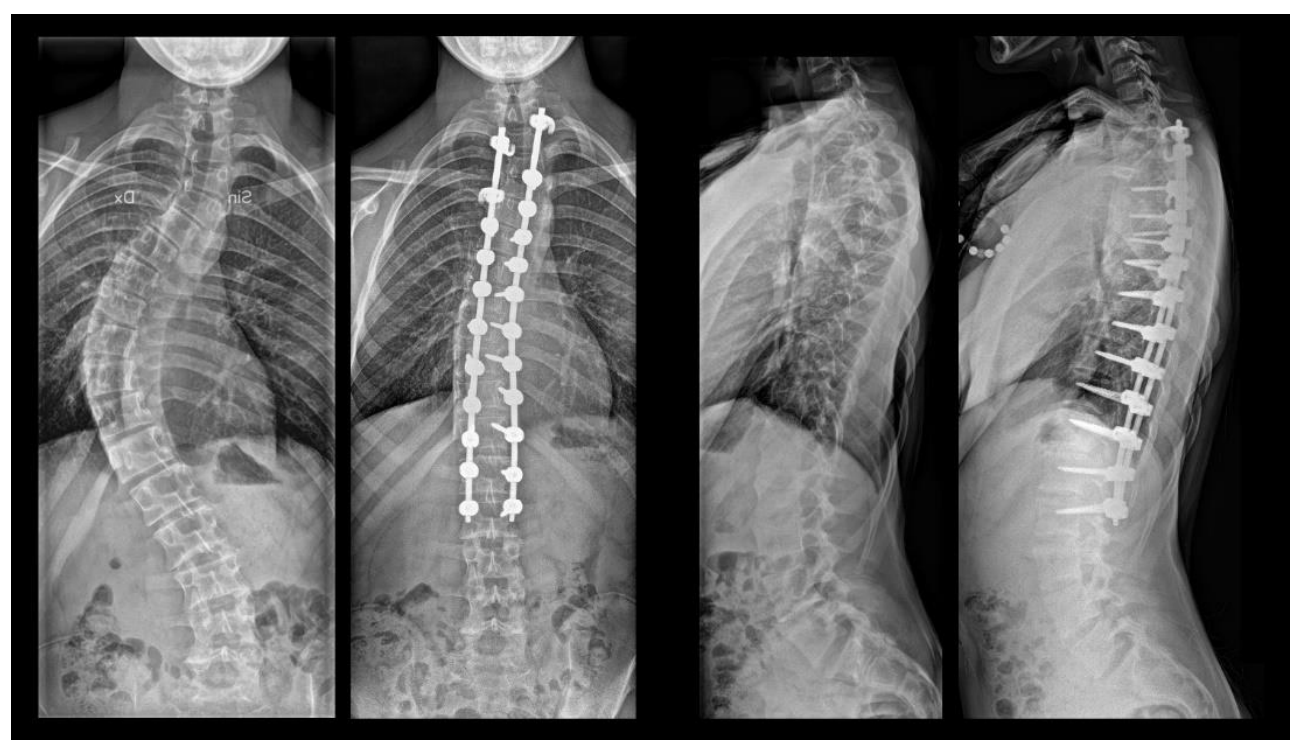

Figure 7. Images from standing radiographs of scoliosis treated with corrective surgery using a psoterior approach.

\section{Anterior approach}

Different techniques have been described for anterior surgery. In 1969, Dwyer et al. introduced a method of fixation of the vertebral bodies with screws connected with braided metal cable, reducing the curve with a tension band on the convex side of the curve (112). The method was later modified by Zielke who connected the screws with a solid metal rod instead (113). Since then, systems with either single or dual rod fixation are available inserted either thoracoscopically or with open surgery $(98,114,115)$. The anterior approach is suited for treating single structural curves either thoracic (Lenke 1) or thoracolumbar (Lenke 5).

Due to local tradition, the method used at our department in Linköping, Sweden, is the Aaro Anterior Spine System (Tresona AB, Malmö, Sweden (116)). The patient is placed in a lateral position and depending on the type of deformity (thoracic or thoracolumbar), a thoracotomy with or without division of the diaphragm is performed. Partial disc excision leaving the posterior part of the anulus and the longitudinal posterior ligament is performed within the chosen segments. Plates are fixed to each vertebral body on the convex side of the curvature. The plates are fixed to each vertebra with two screws through the vertebral body. Final reduction of the curve in the frontal plane is achieved through compression over the plates using 
the principle of a lateral tension band (Figure 8). Thoracic kyphosis is restored by shortening the anterior column. In Lenke 5 curves, the kyphogenic effect of the method is prevented with disc cages used as anterior support to maintain lumbar lordosis.

Because the anterior approaches include discectomies, they are theoretically advantageous in correcting thoracic hypokyphosis (117-119). Generally, fewer levels need to be included in the fixation using anterior methods (120). One major disadvantage is a decline in lung function postoperatively. It remains unclear if this decline is temporary or permanent (120-126).

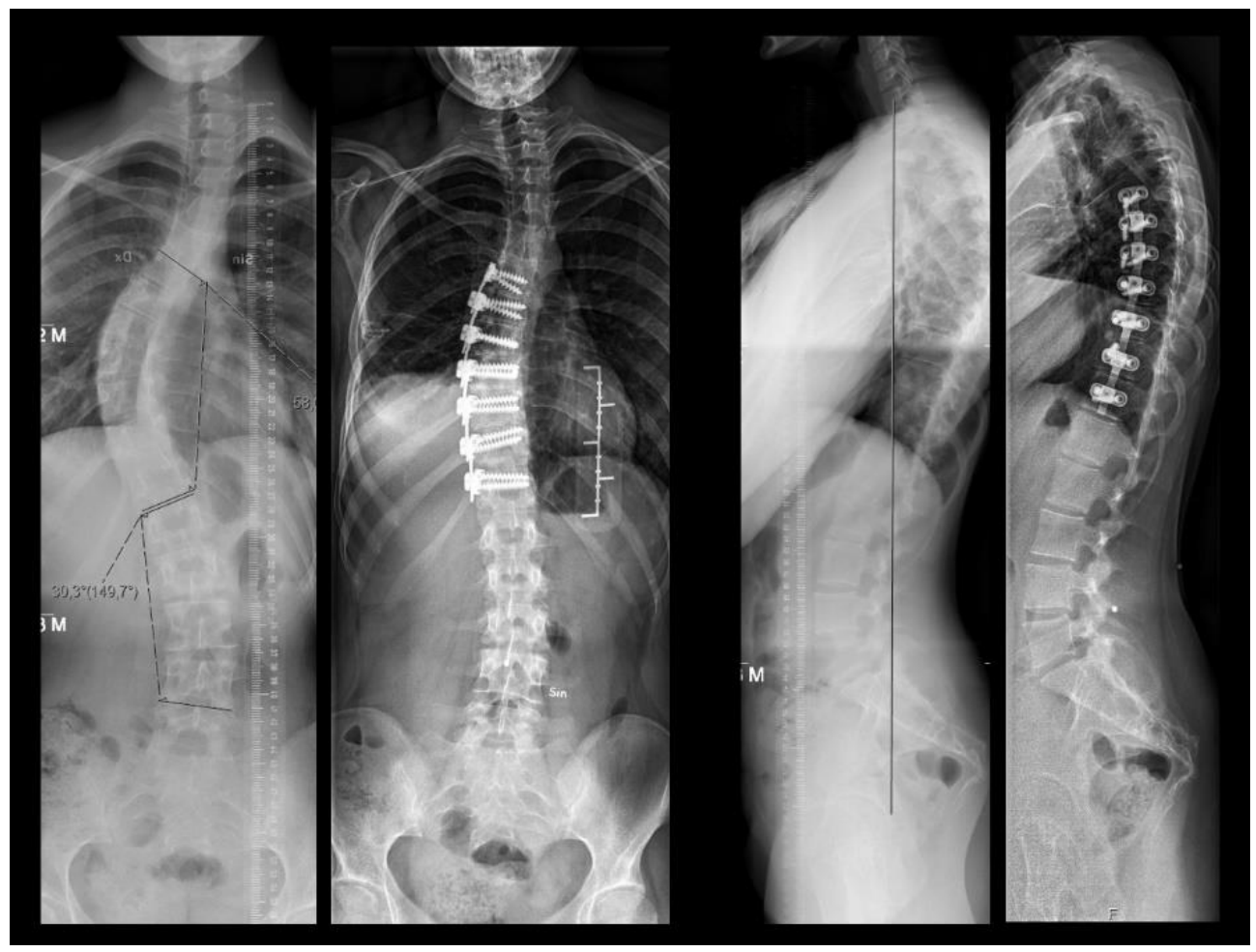

Figure 8. Images from standing radiographs of scoliosis treated with corrctive surgery using an anterior approach.

\section{Selective fusion}

As stated above, the main goals for corrective surgery are to halt curve progression and achieve curve correction to prevent discomfort and pain. This result can be obtained with either anterior or posterior surgery. Both methods result in reduced mobility because the affected segments are fixed. Several studies have shown that long fixations reaching below the level of L3 increase the risk for long-term problems of back pain and lumbar degeneration $(127,128)$. The concept of selective fusion was introduced to prevent unnecessary long fixations to spare motion segments from fixation. 
Moe first introduced this method in 1958, selecting fusion levels based on evaluation of curve flexibility and vertebral rotation (129). According to the Lenke classification, only the structural curves should be included in the fixation; the flexible compensatory curves would correct themselves, making Lenke type 1 and Lenke type 5 appropriate for selective fusion.

Using the anterior approach, fusion from end vertebra to end vertebra is possible $(117,130)$. There is no consensus regarding the level at which posterior instrumentation should end. According to the Lenke classification, posterior fusion should end at the stable vertebra, whereas other studies advocate that the neutral vertebra should be used as the end vertebra of the fixation $(83,131,132)$. The stable vertebra is often one or a few segments below the end vertebra of the curvature. Short posterior instrumentation can lead to add-on phenomenon, i.e., progression of scoliotic deformation due to remaining imbalance of the spine $(131,133)$. Regardless of whether the neutral or stable vertebra is included in the instrumentation, this explains why posterior fixations are longer than anterior fixations even using selective fusion $(117,126)$.

Three-dimensional assessment of the correction obtained by either posterior or anterior approach is addressed in Paper IV. 


\section{Questionnaires}

Treating children with scoliosis is not only about "hard values", such as correcting the deformity and obtaining satisfying postoperative radiographs. "Soft values", such as the patient's quality of life, are of the highest importance. There are many different questionnaires for assessment of function and quality of life for spine and scoliosis patients. The two used in this thesis are the Swedish versions of Scoliosis Research Society-22 Questionnaire (SRS-22) and EuroQol 5 Dimensions 3 Level Questionnaire (EQ5D 3L) (134). Both questionnaires are used in the National Swedish Spine Register, Swespine (135).

\section{SRS-22}

The SRS-22 consists of five domains covered by 22 questions $(136,137)$. Function, pain, selfimage and mental health all have five questions each. The last domain, overall satisfaction, has only two questions. Each question can be answered with one of five alternatives, with corresponding points ranging from 1 (worst score) to 5 (best score).

\section{EQ5D 3L}

This questionnaire consists of the five domains or dimensions: mobility, self-care, usual activities, pain/discomfort, and anxiety/depression $(138,139)$. There are three options for each domain: 1 (no problem), 2 (some/moderate problems), and 3 (very problematic/incapacitating). The result is a five-digit number ranging from 11111 (best possible) to 33333 (worst possible), which is translated into a country specific index. Values from the index range from 1 (maximum quality of life) to -0.594 . A value of zero equals death. This means that, in this questionnaire, it is possible to have a quality of life worse than being dead. In addition, the questionnaire contains a health state scale, "a thermometer", ranging from 0 to 100 (worst to best imaginable health state). 


\section{Aims}

The overall aim was to evaluate the 3D properties of the spine in patients with AIS. Specific aims in respective papers were as follows.

Paper I To compare the Cobb angle in standing and supine images.

Paper II The primary aim of this study was to investigate changes in morphologic parameters in scoliotic vertebrae compared with non-scoliotic vertebrae. The secondary aim was to investigate correlations between these parameters and the Cobb angle.

Paper III To analyze the differences in 3D sagittal pelvic morphology between patients with AIS and asymptomatic adolescents.

Paper IV To describe surgical results in two and three dimensions, as well as patientreported outcomes of scoliosis treatment for Lenke type 1 idiopathic curves with an anterior or posterior approach. 


\section{Patients}

Paper I The population consisted of 128 consecutive patients, with the following attributes:

- A mean age of 15.5 years with a range of 11-26 years

- 97 females and 31 males

- Late-onset idiopathic scoliosis

- Planned for corrective surgery at Linköping University Hospital

The two latter attributes were the inclusion criteria. All Lenke types were represented.

The exclusion criteria were

- Previous spinal surgery

- Atypical curves

Paper II The population consisted of 20 consecutive patients who had corrective surgery planned. The inclusion criteria were

- Late-onset idiopathic scoliosis (LOIS)

- Primary right convex thoracic curves

- Corrective surgery planned

The exclusion criteria were

- Previous spinal surgery

- Atypical curves

A reference group with the following characteristics was included:

- Age and sex matched

- No obvious spine ailments

- No known spine ailments

The mean age was 15.6 years (range, 11-20 years) and 15.7 years (range, 11-21 years) for the respective groups. 
Paper III The population consisted of 37 patients from Linköping University Hospital or Skåne University Hospital in Malmö. All patients were planned for corrective surgery.

The inclusion criteria were

- LOIS

- Corrective surgery planned

The exclusion criteria were

- Previous spinal surgery

- Atypical curves

Data for a reference group $(n=44)$ had previously been collected from the Netherlands. This group had no known spine pathologies or deformities.

The mean age in both groups was the same: 15.4 years (range, 12-21 years) and 15.4 years (range, 12-21 years), respectively.

Paper IV The population consisted of 80 consecutive patients from Linköping University Hospital and Skåne University Hospital in Malmö. All patients had LOIS and required corrective surgery. Forty patients were operated on in Linköping using anterior surgery and 40 patients were operated on in Malmö using posterior surgery.

The exclusion criteria were

- Previous spinal surgery

- Atypical curves

The population was reduced by individuals. One exclusion was due to incomplete low-dose CT examinations. The other was because the individual did not want to participate.

The mean age at time of surgery was 16.1 years (range, 11-26 years) in the group with anterior surgery and 16.4 years (range, 13-22 years) in the group with posterior surgery. 


\section{Methods}

Paper I This paper was a retrospective observational study. One hundred and twenty-eight patients were identified and analyzed between May 2006 and December 2011. The patients met the inclusion criteria as described previously and had undergone corrective surgery at Linköping University Hospital.

All patients had been examined with

- Low-dose CT in a supine position

- Whole-spine radiographs in a standing position

These examinations are done within an hour as part of preoperative planning.

The following data were recorded for all patients:

- Age at preoperative examination

- Lenke classification

- Cobb angles for

- Supine position

- Standing position

Calculations were made of the correlation between the Cobb angle measured from standing and supine images. This was done for both primary and secondary curves. The reliability of the observer was determined by repeating the measurements twice in ten randomly selected patients.

Paper II This paper describes a retrospective study. The population consisted of 20 consecutive patients who met the inclusion criteria. A reference group matching the age and sex criteria was enrolled.

As part of the preoperative procedure, the patients with LOIS were examined with low-dose CT and whole-spine radiographs. The emergency department had examined the reference group with a trauma CT in regular health care.

The Lenke classification was determined from the radiographs.

Using software developed in house, the following were calculated:

- The Cobb angle

- AVR

- Axial vertebral body asymmetry (AVBA)

- Frontal vertebral body rotation (FVBR)

These parameters were also measured at corresponding levels in the control group. 
The CT measurements were performed in the true mid plane of the upper and lower end vertebrae. They were also done in the apex vertebra by multi-planar reconstructions.

The measurements were done independently on different occasions by three different observers.

Paper III This paper describes a retrospective study. The population consisted of patients from Linköping University Hospital and Skåne University Hospital in Malmö. The population descriptors are as follows:

- Female patients from August 2009 to April 2018

- Diagnosed with LOIS

- Planned for corrective surgery

- Examined with pre-operative low-dose CT and whole-spine radiographs

- Spine and both femoral heads visible on the CT scan

CT scans covering both femoral heads are typically not part of the protocol. As a consequence, only 37 patients were identified.

A reference group was included. The population descriptors for the reference group are as follows:

- Non-scoliotic age-matched female patients

- Selected from a pre-existing database

- Had undergone CT imaging of the thorax and abdomen for indications other than spinal pathology, e.g., trauma screening

Curve characteristics were determined on the conventional posterior-anterior and lateral radiographs as well as on the digitally reconstructed lateral radiographs of the supine CT scans. The measurements included

- Cobb angle

- Thoracic kyphosis

- Lumbar lordosis

The true sagittal plane of the pelvis was identified. This was done using a validated 3D method (140). Subsequently, the exact center of the sacral endplate was determined in $3 \mathrm{D}$. This was done by locating the sacral end plate and finding the lines between the left and right edge of the end plate as well as the lines between the anterior and posterior edge of the endplate.

The PI was measured in 3D images. It was defined as the angle between the line connecting the center of the sacral end plate with the hip axis and the line orthogonal to the inclination of the sacral end plate. 
Paper IV This paper describes a retrospective study. The population consisted of patients from Linköping University Hospital and Skåne University Hospital in Malmö. The population descriptors are as follows:

- 40 consecutive patients from each hospital

- Examined with low-dose CT pre- and postoperatively

- MRI used pre-operatively to detect spinal cord anomalies

- Had undergone plain standing posterior-anterior and lateral radiography preoperatively, postoperatively and after 2 years

The surgeries were carried out at the two different hospitals, each using a different surgical approach when performing corrective surgery. Linköping preferred the anterior approach when treating Lenke 1 and 5 curves. Malmö preferred the posterior approach and used it as standard treatment for the correction of all Lenke types.

Conventional posterior-anterior and lateral radiographs were used to determine

- Thoracic kyphosis

- $2 \mathrm{D}$ curve characteristics, including the thoracic and lumbar frontal Cobb angle

- Lumbar lordosis

- Sagittal Cobb angle between the upper and lower instrumented segment

In order to acquire complete spinal reconstructions in a 3D coordinate system, a semi-automatic image processing technique and software developed in Utrecht, the Netherlands, was utilized $(6,33)$.

3D coordinates of individual structures were automatically calculated, taking account of angulation and displacement of each individual level in the three planes. This was done based on manual end plate and spinal canal segmentations; 3D parameters were measured on the pre- and postoperative low-dose CT scans and included

- Vertebral axial rotation

- Anterior-posterior height ratio

- The difference in height of the instrumented part before and after surgery

The vertebral rotation was measured between the apical vertebra and a reference line. This line was defined as the line between the center of the spinal canal and the center of the sternum at level T5.

All patients were asked to complete the SRS-22 and EQ5D 3L questionnaire postoperatively. 


\section{Ethical approval}

The studies in this dissertation have the following ethical approvals from the regional ethics committee in Linköping:

2012/366-31

2013/287-32

2015/220-32. 


\section{Results}

Paper I In this study, the mean Cobb angle was $59^{\circ}\left(\mathrm{SD} 12^{\circ}\right)$ while standing and $48^{\circ}$ (standard deviation [SD] $12^{\circ}$ ) in the supine position, with a mean difference of $11^{\circ}\left(\mathrm{SD} 5^{\circ}\right)$. This applied for all primary curves.

As depicted in Figure 9, the correlation showed an $r$ value of 0.899 (95\% confidence interval [CI], 0.860-0.928) between primary (both thoracic and lumbar) standing and supine images. The intraclass correlation coefficient was 0.969 .

The $\mathrm{r}$ value was 0.340 (95\% CI, $0.177-0.484)$ for the correlation between primary and secondary curves regarding the difference in standing and supine images.

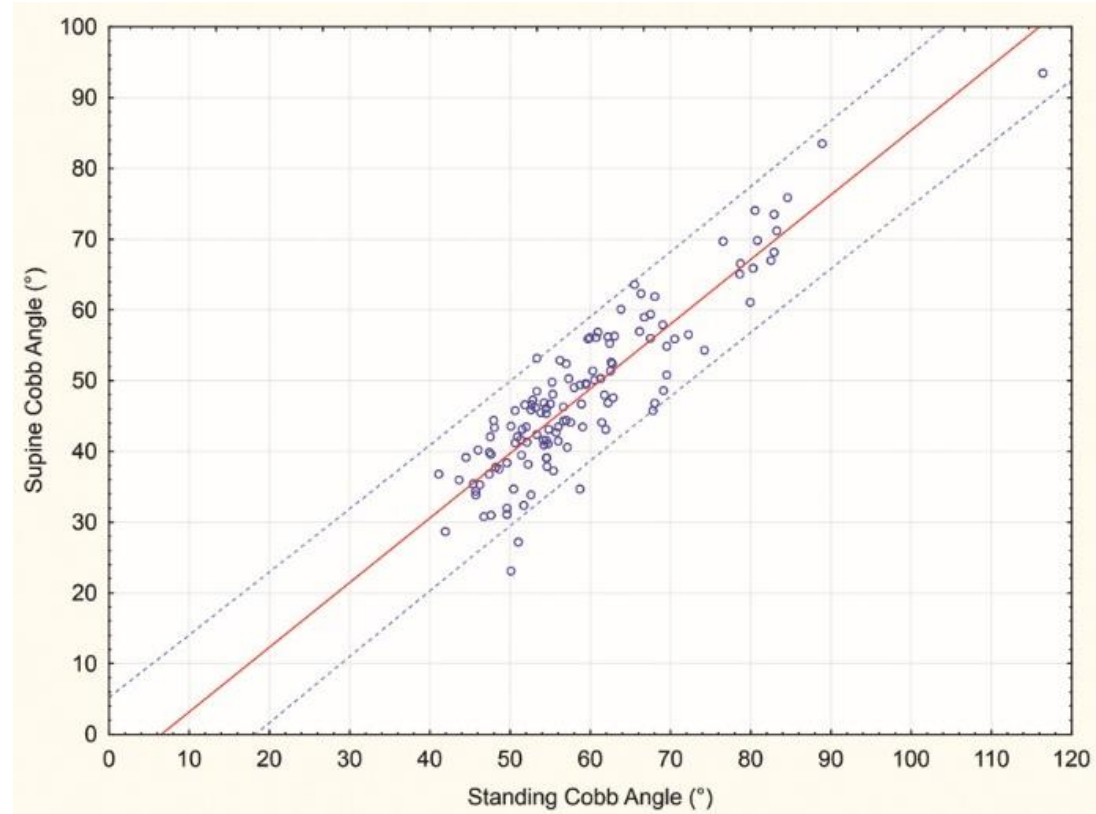

Figure 9. The linear correlation between standing and supine Cobb angles measured for the 128 primary curves, both thoracic and lumbar. Figure reused from Paper I. 
Paper II The results obtained in this study showed a difference between the scoliotic and control groups. The average Cobb angle was $49.3^{\circ}$ for the scoliotic group and $1.3^{\circ}$ for the control group.

There were significant differences in AVR for the patient and control groups. This applied to

- all three vertebrae levels $(\mathrm{p}<0.01)$

- the AVBAs of the superior end and apical vertebrae $(\mathrm{p}<0.008)$

- the FVBR of the apical vertebra $(p=0.011)$

The AVBA and FVBR in the superior end vertebra $(\mathrm{r}=0.728, \mathrm{p}<0.001)$ and in the apical vertebra $(r=0.713, \mathrm{p}<0.001)$ were the only places where statistically significant correlations were found.

The highest level of differences in AVR, AVBA, and FVBR were found at the apical vertebrae. The FVBR provided valuable information for understanding the internal rotation and deformation of vertebrae.

Paper III This study gave the following results.

PI was on average $46.8^{\circ} \pm 12.4^{\circ}$ among the patients with AIS. For the control group, the PI was $41.3^{\circ} \pm 11.4^{\circ}(\mathrm{p}=0.025)$.

The patients with Lenke type 5 showed a higher PI $\left(50.6^{\circ} \pm 16.2^{\circ}\right)$ than found in the control group $(\mathrm{p}=0.042)$. When comparing patients with Lenke type 1 curves $\left(45.9^{\circ} \pm 12.2^{\circ}\right)$ with the control group, there was no significant difference $(\mathrm{p}=$ $0.141)$. 
Paper IV The results in this study showed differences in surgical results using anterior and posterior methods. The study group consisted of 53 Lenke type 1 patients; 26 patients were in the anterior cohort and 27 were in the posterior cohort.

Fewer vertebrae were instrumented in the anterior cohort. This resulted in a smaller number of implanted screws $(\mathrm{p}<0.001)$. The surgery time and intraoperative blood loss were smaller $(\mathrm{p}<0.001)$ in the anterior group compared with the posterior group.

Directly after surgery, the Cobb angle correction of the primary thoracic curve was $32.1^{\circ} \pm 10.3^{\circ}(57 \% \pm 12 \%)$ in the anterior cohort. The result for the posterior cohort was $34.7^{\circ} \pm 7.2^{\circ}(73 \% \pm 12 \%)(\mathrm{p}<0.001)$.

At the 2-year follow-up, the corrections compared with preoperatively were $30.9^{\circ}$ $\pm 10.3^{\circ}(55 \% \pm 13 \%)$ for the anterior cohort and $31.7^{\circ} \pm 7.2^{\circ}(66 \% \pm 12 \%)(\mathrm{p}=$ 0.001 ) for the posterior cohort (Figure 10).

There were no significant differences between the cohorts at the 2-year follow-up with regard to the following:

- Lumbar curve correction

- Thoracic kyphosis

- Lumbar lordosis

- Postoperative alignment restoration in 3D

- Questionnaires

The mean follow-up time for the questionnaires was 50 months for the posterior cohort and 43 months for the anterior cohort.

\section{Curve Correction}

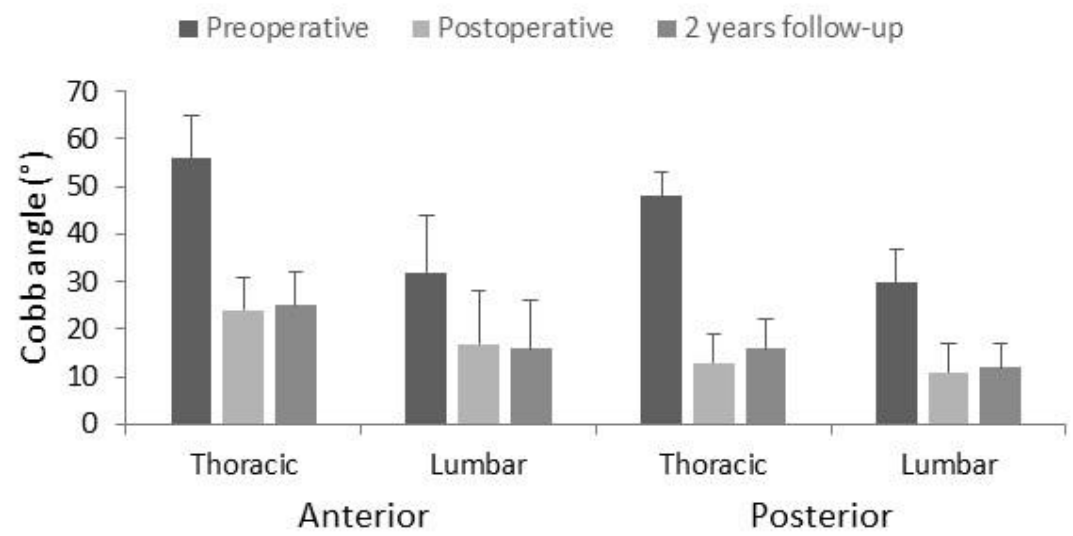

Figure 10. The thoracic and lumbar Cobb angles for Lenke type 1 curves treated with an anterior or posterior approach. Error bars indicate SD. Figure reused from Paper IV. 


\section{Strengths and limitations}

Paper I The material in this study is extensive compared with similar studies. The study group consists of both males and females. The patients have thoracic as well as lumbar deformities. Moderate to severe deformities are covered (Cobb angles ranging from $40^{\circ}$ to $116^{\circ}$ ), and the examinations are performed days before the planned corrective surgery.

Standing and supine examinations appear to have a linear relationship within the range of Cobb angles examined.

A limitation of the study is the absence of information on the relationship with smaller curves that are not yet considered candidates for surgery. Another limitation is that only one observer performed all the measurements.

Paper II The results in this study provide methods for assessment of vertebral asymmetry and for describing the 3D deformation of the vertebrae in the scoliotic spine. The innovative FVBR measurement described in this study should be considered in further studies of vertebral asymmetry as a new parameter of value. This applies also to further study of the spinal longitudinal ligaments and their role when viewed in relation to vertebral rotation as well as skeletal remodeling and overgrowth. More automated software for both data gathering and initial analysis would increase the reliability of the method and make the results more reproduceable.

Paper III The method used in this study enables an assessment of the PI from a 3D perspective. The material in this study is, however, limited because both femoral heads must be included in the examination. This is not part of the standard lowdose CT protocol.

Paper IV This study shows to what degree 3D correction is achieved by corrective surgery. The evaluation includes the radiologic outcome, the sustained level of correction during the follow-up period, and the patient's perceived quality of life. Pulmonary evaluation was not performed in this study. Such information would have contributed to a more comprehensive overview of the results from the different approaches. 


\section{Discussion}

\section{Positioning of the patient at radiologic evaluation}

In recent years, the Scoliosis Research Society and various clinicians have suggested that 3D reconstructions are needed to increase the quality of scoliosis treatment $(10,141,142)$. Presently, true 3D reconstructions can only be obtained from examinations using CT or MRI. Both these methods are carried out in the supine position. It was therefore important to investigate how the Cobb angle is affected by changing from a standing to a supine position.

In Paper I, the results showed that there was a strong correlation between Cobb angle measurement in the standing and supine positions. The difference was constant irrespective of the size of the curvature (standing Cobb angle ranging from $40^{\circ}$ to $120^{\circ}$ ) or location in the lumbar or thoracic spine. The difference found was absolute rather than proportional.

The findings are consistent with the findings of Torell et al. (64). However, Torell et al. did not differentiate between lumbar and thoracic curves and did not include males in the study population.

Compared with previous studies, the difference of $11.1^{\circ}$ for primary curves was slightly larger in our study (8.9, Torell et al. (64); 7.6 ${ }^{\circ}$, Wessberg et al. (65), $10.0^{\circ}$, Lee et al. (66)). The current study also expanded the scope compared with Torell et al. and Wessberg et al. The result of $7.8^{\circ}$ for secondary curves was consistent with the findings of Lee et al.

In conclusion, using larger and more diversified material, our results support the findings of previous studies. It was somewhat surprising that the difference between supine and standing Cobb angles was of similar magnitude for the entire range of curves investigated.

A possible explanation for this finding is that once the deformity has become structural, this difference is inherent. This could explain why gravity does not seem to affect larger curves more than smaller ones.

\section{Vertebral asymmetry in the axial plane}

The pedicular asymmetry and deformation in scoliotic vertebrae has been the subject of numerous studies to assess screw placement. The primary aim in Paper II was to provide a description of the deformation in the axial plane of the vertebral bodies of upper and lower end vertebrae as well as the apical vertebra in patients with AIS.

This study confirmed the results from numerous previous studies regarding vertebral rotation. All vertebrae examined (i.e., upper and lower end vertebrae as well as the apical vertebra) had a larger AVR compared with the corresponding vertebrae in the reference group $(69,70,143)$.

AVBA and FVBR are innovative measures applied in our study. AVBA and FVBR provide knowledge regarding vertebral deformation in the axial plane. Both measures showed that the highest level of deformation and rotation is found in the apical vertebra. This confirms that this 
region in the scoliotic spine is the most affected. The AVBA was used to measure vertebral asymmetry and showed a small absolute difference between the patient group and the reference group. In our study, this was valid even for vertebrae with highly pronounced asymmetry. The difference was only 0.030 at the apex $(0.949$ vs $0.979 ; \mathrm{p}<0.001)$, where the asymmetry was most prominent.

FVBR is more sensitive and reveals vertebral asymmetry even with small differences in AVBA by describing the internal rotation in the vertebral body (Figure 11). A significant internal rotation toward the concavity of the curve in the frontal plane for the apical vertebra was shown by the FVBR, in contrast to the overall rotated AVR toward the convexity of the curvature in patients with scoliosis compared with the control group.

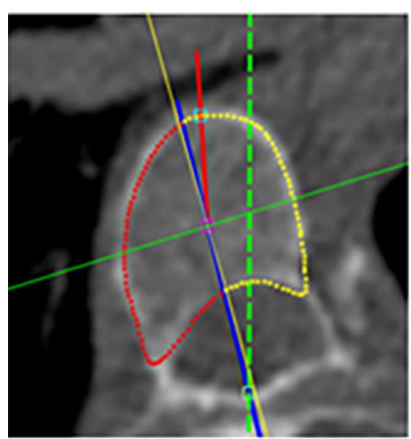

(a)

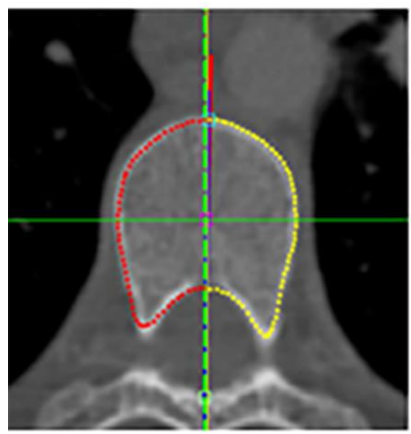

(d)

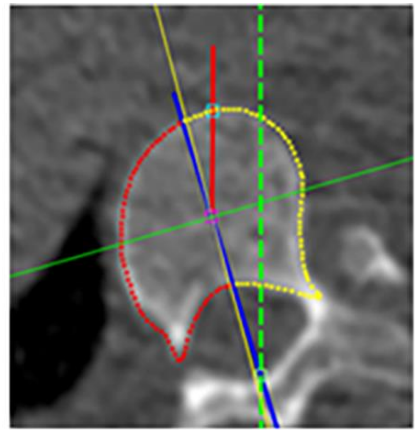

(b)

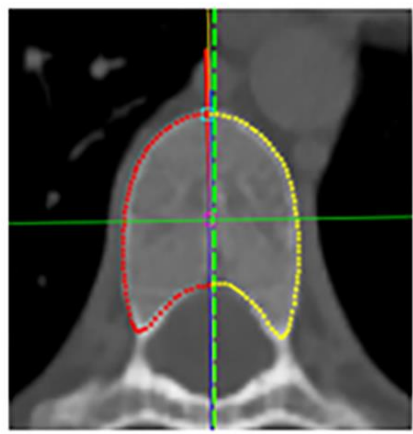

(e)

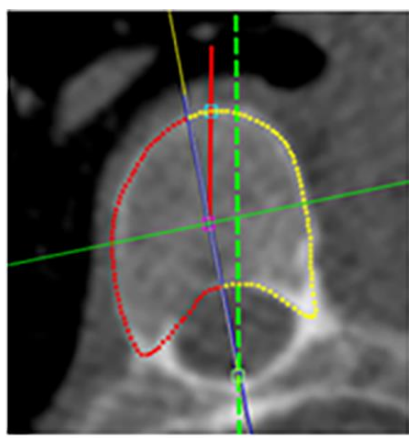

(c)

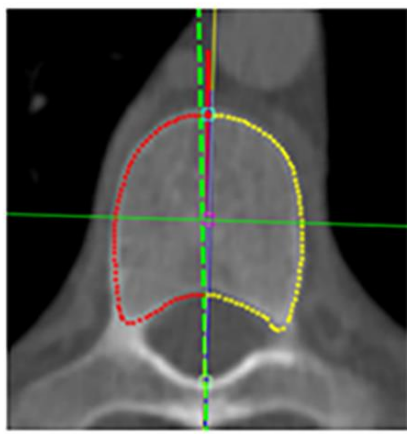

(f)

Figure 11. Comparison of AVBA measurements between scoliotic (top row) and control (bottom row) vertebrae. The AVBA is the comparison between the right (red outline) and the left (yellow outline) halves of the vertebral body. The panels show the superior end vertebra (left), the apical vertebra (middle) and the inferior end vertebra (right) in the most deformed scoliotic vertebrae (a-c, AVBA 0.84, 0.88, and 0.90, respectively) and in a representative of the control group ( $d-f, A V B A 0.99$ for all). The angle between the blue line and the vertical red line is the FVBR, which illustrates the internal vertebral deformation. Figure reused from Paper II. 
Schlösser et al. reported a strong correlation between the Cobb angle and the AVR (33). We found only a poor correlation in our study. We could only find strong correlation between AVBA-FVBR when comparing the Cobb angle, AVR, AVBA, and FVBR, for the superior end vertebra and apical vertebra $(R=0.728$ and -0.713 , respectively).

Relying on the Cobb angle alone in the assessment of the severity of deformity thus appears insufficient. The poor correlation between the Cobb angle and the other parameters describing rotation and asymmetry indicates the need for additional parameters to fully describe the scoliotic spine. We consider the FVBR to be a promising parameter, worth including in an assessment. It not only detects vertebral asymmetry but could also reveal if the deformity is primarily due to skeletal overgrowth (according to Heuter-Volkmann's law) or due to vertebral rotation. This could be possible through future studies on the relationship between the anterior longitudinal ligament and the point where FVBR crosses the anterior cortex.

\section{Pelvic incidence}

We concluded that the PI was higher in patients with Lenke type 5 curves compared with patients with Lenke type 1 curves as well as a reference group (Paper III).

When reviewing previous studies based on radiographs, we found a variation of the PI between $41^{\circ}$ and $49^{\circ}$ for non-scoliotic adolescents and between $42^{\circ}$ and $57^{\circ}$ for AIS patients $(74,140$, 144-152).

Previous studies argue whether there is any difference in PI between patients with AIS compared with non-scoliotic controls $(74,144-147,149,153)$. Some minor differences regarding PI between studies could be explained by the inaccuracy of the $2 \mathrm{D}$ methods used but also by the different age structures because the PI increases with age until the end of adolescence $(154,155)$.

Vrtovec et al. described the 3D PI of a non-scoliotic population using CT examinations, demonstrating improved accuracy compared with the traditional measurements on sagittal radiographs (140).

In previous studies, the PI of patients with AIS was based only on 2D radiographs, whereas our measurement of the PI utilized low-dose CT data and accurate image processing techniques as described by Vrtovec et al. (140). We found a higher PI in Lenke type 5 curves than in Lenke type 1 curves. This is contradictory to Mac-Thiong et al. and Farshad et al. who found that the scoliotic curve type was not associated with a specific pattern of sagittal pelvic morphology and balance $(144,145)$. 


\section{Previous studies have shown that}

- An excess of posterior shear loads causes a decrease in the rotational stiffness of the involved segments.

- The only vertebrae that take part in the development of scoliotic curve patterns are the vertebrae that are posteriorly inclined.

- Vertebrae that are more posteriorly inclined are rotationally less stable and could lead to initiation and progression of AIS $(24,32,150,152)$.

It is consistent with these assumptions that the PI in our study was higher among patients with Lenke type 5 curves compared with patients with Lenke type 1 curves and controls. This indicates that the PI is part of the etiopathogenesis of AIS as well as a determining factor for the curve type. However, it was not possible to determine the exact role of the PI in our crosssectional study.

We avoided bias due to image acquisition or patient positioning by using the 3D CT measurement method. Only moderate to severe AIS curves, and no mild AIS curves, were included in this study because all scans were acquired preoperatively. The examinations were made in the supine position. As shown by Philippot et al. the position (standing, supine, or sitting) has no influence on the PI (156).

\section{Corrective surgery}

The outcomes of spinal fusion in patients with Lenke curve type 1 using posterior or anterior instrumentation were described in Paper IV. Both approaches resulted in 3D reduction of the deformity. Fewer vertebrae were instrumented in shorter surgery time and with less blood loss using the anterior approach compared with the posterior approach. The posterior approach achieved a better frontal curve correction based on radiographs.

The anterior cohort showed a larger main thoracic Cobb angle preoperatively. Naturally stiffer curves could lead to less correction. The (un-instrumented) secondary lumbar curves were reduced in both cohorts without any statistically significant difference. This indicates that a correction of the primary curve is enough to reduce the lumbar secondary curves in Lenke 1 deformities.

There was no change in the frontal correction in the anterior cohort during the follow-up time. There was a minor loss of correction in the posterior cohort, from $13^{\circ} \pm 6^{\circ}$ to $16^{\circ} \pm 6^{\circ}(\mathrm{p}=$ 0.004). Apart from the shorter surgical time in the anterior cohort, the results from our study were well in line with those reported by Newton et al. (126).

Previously, it has been stated that the posterior approach is not fully able to restore thoracic kyphosis, and that anterior spinal instrumentation is most likely superior in restoring thoracic kyphosis $(118,126,157)$. In our study, the anterior approach showed an increase in kyphosis of $8^{\circ} \pm 9^{\circ}$ compared to $2^{\circ} \pm 9^{\circ}$ in the posterior cohort. The difference between the groups was not significant. 
Two-dimensional images of the spine do not provide sufficient presentation of the actual sagittal alignment due to the rotation of scoliotic vertebrae. Consequently, sagittal alignment in the true sagittal plane was studied using low-dose CT scans. Regarding sagittal plane restoration, there were no significant differences identified between the approaches. After surgery, a significant kyphogenic effect was observed. Sagittal alignment was not restored to the physiologic thoracic kyphosis of the controls described by Brink et al. (29).

The negative effect on pulmonary function is an obvious concern regarding the anterior approach. Previous studies have described that the anterior approach results in deterioration of pulmonary function values (i.e., total lung capacity, vital capacity, forced expiratory volume, and residual volume) postoperatively compared with the posterior approach (121-126). However, Nohara et al. performed a 10-year follow-up with no significant differences in pulmonary function (120). Pulmonary evaluation is not included in this study because it was not part of the standard care postoperatively. This is a major limitation of our study.

A decrease in pulmonary function could affect the perceived quality of life with regard to discomfort, function, health state, and overall life satisfaction. These aspects are included in the questionnaires and may be used as a proxy for pulmonary function. The patient scores were high on the SRS-22 and EQ-5D-3L questionnaires, without significant differences between the anterior and posterior cohorts postoperatively.

Infection risk may be increased by posterior surgery as shown in a multitude of studies (109111). We could not confirm this in our study. 


\section{Conclusions}

The scoliotic spine is a complex deformity in three dimensions. This is shown repeatedly in this thesis. The Cobb angle changes due to the force of gravity acting on the spine and affecting it differently in different positions. It is not only the scoliotic spine that is deformed; the deformation is also seen within every single vertebra in the deformity.

Different patterns of pelvic morphology and configuration seem to affect the very foundation of the spine, predisposing it to different types of scoliotic curves. Corrective surgery, using the posterior or anterior approach, changes the biomechanics and anatomy in the spine in different ways.

Understanding the 3D properties of the deformity is essential for increasing our knowledge regarding this type of spinal deformity, making it less idiopathic.

Further biomechanical analysis could reveal whether the deformity is primarily due to skeletal overgrowth or due to vertebral rotation. This would provide valuable insights on the cause of idiopathic scoliosis, making predictions of prognosis more precise and effective. Furthermore, treatment, both surgical and non-surgical, could become more individualized and optimized to meet the specific needs and demands of every patient with a scoliotic deformity. 


\section{Future research}

There is still a lot of research to be done on the 3D aspects of AIS. Further development of hardware for imaging is probably a corner-stone to achieve a higher level of understanding.

CT provides opportunities for very detailed analysis of the skeletal structures, and so do 3Dreconstructions, but at the expense of exposure to ionized radiation. It is important to further reduce the radiation dosage even for low-dose CT examinations to achieve safe and feasible options in the everyday care of idiopathic scoliosis.

MRI is superior for assessing soft tissue and nervous structures without exposing the patient to ionizing radiation. MRI could become the preferred method for diagnostics in scoliosis through development of sequences and modalities suitable for investigating not only soft tissue but also skeletal structures. Such sequences could also be used in investigations of the relationship between the anterior longitudinal ligament and the position of FVBR (described in Paper II). This would provide insight into whether the vertebral morphology is mainly changed due to skeletal overgrowth or because of vertebral rotation caused by muscles and ligaments.

Axially loaded/standing CT and MRI would provide the possibility of detailed assessment of the spine under conditions similar to those with standing radiographs.

More automated software in the work-up of radiology and imaging would allow more standardized, precise, and reliable measurements, thus reducing the subjectivity of the observer.

The pulmonary effects pre- and postoperatively of corrective surgery should be investigated. How is lung function affected? Is the decline seen in anterior surgery only temporary or permanent? Is there any level of pulmonary dysfunction when anterior surgery is contraindicated?

An interdisciplinary collaboration between medical and technical professions and the industry is not only desirable but also a necessity to find solutions to many of the remaining challenges associated with idiopathic scoliosis. 


\section{Acknowledgments}

As anyone who has ever worked on a thesis knows, it is not something one does by their lonesome. There are some people I would like to acknowledge a little bit more for their contributions to this thesis.

First of all, I am grateful to Professor Hans Tropp for being my main supervisor, always having an open door, being a friend, and having enormous patience with me. Daniel Forsberg, Nils Dahlström and Staffan Wirell have been my co-supervisors and the support you have provided in your different areas of expertise has been invaluable. To my colleagues at the department, thank you for your cheering and support - it has been much needed at times and always appreciated.

A special thank you to Professor René Castelein for enabling the cooperation with the Utrecht group. Rob Brink, without you this would have been much harder and a lot duller. You are always welcome for a fika. To Acke Ohlin and Kasim Abul-Kasim for making the cooperation with the Malmö group possible.

To the Hillmo family, for your friendship and inspiration long before the beginning of the project ending up in this thesis.

Till Sparvöga, för din inspiration, din härliga energi och för dina fina teckningar.

A special thank you to my parents Helen and Ludek for your never-ending love and encouragement - those long days going through the early drafts of this thesis have certainly helped tremendously - and to my siblings Veronika, Denisa, and Lucas for your understanding and support.

To P-A and Anneli, thank you for giving me perspective when the workload was nearly too much.

Evelyn and Alva, my beloved daughters, I promise to spend more time with you in the playground from now on.

Camilla, my wife. What you have put up with for this thesis to come into being can't be expressed in words; without you this would have been impossible in so many ways. Thank you for being my biggest supporter and my personal cheerleader. 


\section{References}

1. Adams W. Lectures on the Pathology and Treatment of Lateral and Other Forms of Curvature of the Spine. London: Churchill; 1865.

2. Somerville EW. Rotational lordosis; the development of single curve. J Bone Joint Surg Br. 1952;34-b(3):421-7.

3. Roaf R. The basic anatomy of scoliosis. J Bone Joint Surg Br. 1966;48(4):78692.

4. Cobb J. Outline for the study of scoliosis. Instructional Course Lectures. 1948;5:261-75.

5. Janssen MM, Kouwenhoven JW, Schlosser TP, Viergever MA, Bartels LW, Castelein RM, et al. Analysis of preexistent vertebral rotation in the normal infantile, juvenile, and adolescent spine. Spine (Phila Pa 1976). 2011;36(7):E48691.

6. Kouwenhoven JW, Vincken KL, Bartels LW, Castelein RM. Analysis of preexistent vertebral rotation in the normal spine. Spine (Phila Pa 1976). 2006;31(13):1467-72.

7. Kouwenhoven JW, Bartels LW, Vincken KL, Viergever MA, Verbout AJ, Delhaas $\mathrm{T}$, et al. The relation between organ anatomy and pre-existent vertebral rotation in the normal spine: magnetic resonance imaging study in humans with situs inversus totalis. Spine (Phila Pa 1976). 2007;32(10):1123-8.

8. Scoliosis Research Society Terminology Committee and Working Group on Spinal Classification Revised Glossary of Terms [cited 2018 August/8]. Available from: https://www.srs.org/professionals/online-education-andresources/glossary/revised-glossary-of-terms.

9. Stokes IA. Three-dimensional terminology of spinal deformity. A report presented to the Scoliosis Research Society by the Scoliosis Research Society Working Group on 3-D terminology of spinal deformity. Spine (Phila Pa 1976). 1994;19(2):236-48.

10. Labelle H, Aubin CE, Jackson R, Lenke L, Newton P, Parent S. Seeing the spine in 3D: how will it change what we do? J Pediatr Orthop. 2011;31(1 Suppl):S3745.

11. Abul-Kasim K, Overgaard A, Maly P, Ohlin A, Gunnarsson M, Sundgren PC. Low-dose helical computed tomography (CT) in the perioperative workup of adolescent idiopathic scoliosis. Eur Radiol. 2009;19(3):610-8. 
12. Illes T, Tunyogi-Csapo M, Somoskeoy S. Breakthrough in three-dimensional scoliosis diagnosis: significance of horizontal plane view and vertebra vectors. Eur Spine J. 2011;20(1):135-43.

13. Moramarco M, Weiss HR. Congenital Scoliosis. Curr Pediatr Rev. 2015.

14. Vialle R, Thevenin-Lemoine C, Mary P. Neuromuscular scoliosis. Orthop Traumatol Surg Res. 2013;99(1 Suppl):S124-39.

15. Aebi M. The adult scoliosis. Eur Spine J. 2005;14(10):925-48.

16. James JI. Idiopathic scoliosis; the prognosis, diagnosis, and operative indications related to curve patterns and the age at onset. J Bone Joint Surg Br. 1954;36b(1):36-49.

17. Skaggs DL GT, El-Hawary R, Emans J, Mendelow M, Smith J. Early Onset Scoliosis Consensus Statement, SRS Growing Spine Committee, 2015. Spine Deform. 2015;3(2):107.

18. Konieczny MR, Senyurt H, Krauspe R. Epidemiology of adolescent idiopathic scoliosis. J Child Orthop. 2013;7(1):3-9.

19. Weinstein SL. Natural history. Spine (Phila Pa 1976). 1999;24(24):2592-600.

20. Weinstein SL, Dolan LA, Cheng JC, Danielsson A, Morcuende JA. Adolescent idiopathic scoliosis. Lancet. 2008;371(9623):1527-37.

21. Dunn J, Henrikson NB, Morrison CC, Blasi PR, Nguyen M, Lin JS. Screening for adolescent idiopathic scoliosis: evidence report and systematic review for the US Preventive Services Task Force. JAMA. 2018;319(2):173-87.

22. Negrini S, Aulisa AG, Aulisa L, Circo AB, de Mauroy JC, Durmala J, et al. 2011 SOSORT guidelines: orthopaedic and rehabilitation treatment of idiopathic scoliosis during growth. Scoliosis. 2012;7(1):3.

23. Schlosser TP, van der Heijden GJ, Versteeg AL, Castelein RM. How 'idiopathic' is adolescent idiopathic scoliosis? A systematic review on associated abnormalities. PLoS One. 2014;9(5):e97461.

24. Kouwenhoven JW, Smit TH, van der Veen AJ, Kingma I, van Dieen JH, Castelein RM. Effects of dorsal versus ventral shear loads on the rotational stability of the thoracic spine: a biomechanical porcine and human cadaveric study. Spine (Phila Pa 1976). 2007;32(23):2545-50.

25. Janssen MM, Vincken KL, Kemp B, Obradov M, de Kleuver M, Viergever MA, et al. Pre-existent vertebral rotation in the human spine is influenced by body position. Eur Spine J. 2010;19(10):1728-34. 

al. Posteriorly directed shear loads and disc degeneration affect the torsional stiffness of spinal motion segments: a biomechanical modeling study. Spine (Phila Pa 1976). 2013;38(21):E1313-9.

27. Oxland TR. Fundamental biomechanics of the spine--What we have learned in the past 25 years and future directions. J Biomech. 2016;49(6):817-32.

28. Lenke LG, Betz RR, Harms J, Bridwell KH, Clements DH, Lowe TG, et al. Adolescent i diopathic scoliosis: a new classification to determine extent of spinal arthrodesis. J Bone Joint Surg Am. 2001;83-a(8):1169-81.

29. Brink RC, Schlosser TPC, Colo D, Vavruch L, van Stralen M, Vincken KL, et al. Anterior spinal overgrowth is the result of the scoliotic mechanism and is located in the disc. Spine (Phila Pa 1976). 2017;42(11):818-22.

30. Dickson RA, Lawton JO, Archer IA, Butt WP. The pathogenesis of idiopathic scoliosis. Biplanar spinal asymmetry. J Bone Joint Surg Br. 1984;66(1):8-15.

31. Guo X, Chau WW, Chan YL, Cheng JC. Relative anterior spinal overgrowth in adolescent idiopathic scoliosis. Results of disproportionate endochondralmembranous bone growth. J Bone Joint Surg Br. 2003;85(7):1026-31.

32. Castelein RM, van Dieen JH, Smit TH. The role of dorsal shear forces in the pathogenesis of adolescent idiopathic scoliosis--a hypothesis. Med Hypotheses. 2005;65(3):501-8.

33. Schlosser TP, van Stralen M, Brink RC, Chu WC, Lam TP, Vincken KL, et al. Three-dimensional characterization of torsion and asymmetry of the intervertebral discs versus vertebral bodies in adolescent idiopathic scoliosis. Spine (Phila Pa 1976). 2014;39(19):E1159-66.

34. Little JP, Izatt MT, Labrom RD, Askin GN, Adam CJ. Investigating the change in three dimensional deformity for idiopathic scoliosis using axially loaded MRI. Clin Biomech (Bristol, Avon). 2012;27(5):415-21.

35. Kotwicki T, Napiontek M. Intravertebral deformation in idiopathic scoliosis: a transverse plane computer tomographic study. J Pediatr Orthop. 2008;28(2):2259.

36. Harrop JS, Birknes J, Shaffrey CI. Noninvasive measurement and screening techniques for spinal deformities. Neurosurgery. 2008;63(3 Suppl):46-53.

37. Cote P, Kreitz BG, Cassidy JD, Dzus AK, Martel J. A study of the diagnostic accuracy and reliability of the Scoliometer and Adam's forward bend test. Spine (Phila Pa 1976). 1998;23(7):796-802; discussion 803. 
38. Murrell GA, Coonrad RW, Moorman CT, 3rd, Fitch RD. An assessment of the reliability of the Scoliometer. Spine (Phila Pa 1976). 1993;18(6):709-12.

39. Simony A, Hansen EJ, Christensen SB, Carreon LY, Andersen MO. Incidence of cancer in adolescent idiopathic scoliosis patients treated 25 years previously. Eur Spine J. 2016;25(10):3366-70.

40. Goldberg MS, Mayo NE, Levy AR, Scott SC, Poitras B. Adverse reproductive outcomes among women exposed to low levels of ionizing radiation from diagnostic radiography for adolescent idiopathic scoliosis. Epidemiology (Cambridge, Mass). 1998;9(3):271-8.

41. Doody MM, Lonstein JE, Stovall M, Hacker DG, Luckyanov N, Land CE. Breast cancer mortality after diagnostic radiography: findings from the U.S. Scoliosis Cohort Study. Spine (Phila Pa 1976). 2000;25(16):2052-63.

42. Ronckers CM, Land CE, Miller JS, Stovall M, Lonstein JE, Doody MM. Cancer mortality among women frequently exposed to radiographic examinations for spinal disorders. Radiat Res. 2010;174(1):83-90.

43. Ron E, Lubin JH, Shore RE, Mabuchi K, Modan B, Pottern LM, et al. Thyroid cancer after exposure to external radiation: a pooled analysis of seven studies. Radiat Res. 1995;141(3):259-77.

44. Nash CL, Jr., Gregg EC, Brown RH, Pillai K. Risks of exposure to X-rays in patients undergoing long-term treatment for scoliosis. J Bone Joint Surg Am. 1979;61(3):371-4.

45. The 2007 Recommendations of the International Commission on Radiological Protection. ICRP publication 103. Ann ICRP. 2007;37(2-4):1-332.

46. De Smet AA, Fritz SL, Asher MA. A method for minimizing the radiation exposure from scoliosis radiographs. J Bone Joint Surg Am.1981;63(1):156-61.

47. Geijer H, Beckman K, Jonsson B, Andersson T, Persliden J. Digital radiography of scoliosis with a scanning method: initial evaluation. Radiology. 2001;218(2):402-10.

48. Geijer H, Verdonck B, Beckman KW, Andersson T, Persliden J. Digital radiography of scoliosis with a scanning method: radiation dose optimization. Eur Radiol. 2003;13(3):543-51.

49. Klepps SJ, Lenke LG, Bridwell KH, Bassett GS, Whorton J. Prospective comparison of flexibility radiographs in adolescent idiopathic scoliosis. Spine (Phila Pa 1976). 2001;26(5):E74-9. 
50. Dubousset J, Charpak G, Dorion I, Skalli W, Lavaste F, Deguise J, et al. [A new 2D and 3D imaging approach to musculoskeletal physiology and pathology with low-dose radiation and the standing position: the EOS system]. Bull Acad Natl Med. 2005;189(2):287-97; discussion 97-300[in French].

51. Ilharreborde B, Dubousset J, Le Huec JC. Use of EOS imaging for the assessment of scoliosis deformities: application to postoperative 3D quantitative analysis of the trunk. Eur Spine J. 2014;23 Suppl 4:S397-405.

52. Pedersen PH, Petersen AG, Ostgaard SE, Tvedebrink T, Eiskjaer SP. EOS(R) Micro-dose protocol: first full-spine radiation dose measurements in anthropomorphic phantoms and comparisons with EOS standard-dose and conventional digital radiology (CR). Spine (Phila Pa 1976). 2018.

53. Kalra MK, Quick P, Singh S, Sandborg M, Persson A. Whole spine CT for evaluation of scoliosis in children: feasibility of sub-milliSievert scanning protocol. Acta Radiol. 2013;54(2):226-30.

54. Abul-Kasim K, Overgaard A, Ohlin A. Dural ectasia in adolescent idiopathic scoliosis: quantitative assessment on magnetic resonance imaging. Eur Spine J. 2010;19(5):754-9.

55. Faloon M, Sahai N, Pierce TP, Dunn CJ, Sinha K, Hwang KS, et al. Incidence of neuraxial abnormalities is approximately $8 \%$ among patients with adolescent idiopathic scoliosis: a meta-analysis. Clin Orthop Relat Res. 2018;476(7):150613.

56. Inoue M, Minami S, Nakata Y, Otsuka Y, Takaso M, Kitahara H, et al. Preoperative MRI analysis of patients with idiopathic scoliosis: a prospective study. Spine (Phila Pa 1976). 2005;30(1):108-14.

57. Ouellet JA, LaPlaza J, Erickson MA, Birch JG, Burke S, Browne R. Sagittal plane deformity in the thoracic spine: a clue to the presence of syringomyelia as a cause of scoliosis. Spine (Phila Pa 1976). 2003;28(18):2147-51.

58. Suzuki S, Yamamuro T, Shikata J, Shimizu K, Iida H. Ultrasound measurement of vertebral rotation in idiopathic scoliosis. J Bone Joint Surg Br. 1989;71(2):2525 .

59. Wang Q, Li M, Lou EH, Wong MS. Reliability and Validity Study of Clinical Ultrasound Imaging on Lateral Curvature of Adolescent Idiopathic Scoliosis. PLoS One. 2015;10(8):e0135264.

60. Brink RC, Wijdicks SPJ, Tromp IN, Schlosser TPC, Kruyt MC, Beek FJA, et al. A reliability and validity study for different coronal angles using ultrasound imaging in adolescent idiopathic scoliosis. Spine J. 2018;18(6):979-85. 
61. Adam CJ, Izatt MT, Harvey JR, Askin GN. Variability in Cobb angle measurements using reformatted computerized tomography scans. Spine (Phila Pa 1976). 2005;30(14):1664-9.

62. Carman DL, Browne RH, Birch JG. Measurement of scoliosis and kyphosis radiographs. Intraobserver and interobserver variation. J Bone Joint Surg Am. 1990;72(3):328-33.

63. Morrissy RT, Goldsmith GS, Hall EC, Kehl D, Cowie GH. Measurement of the Cobb angle on radiographs of patients who have scoliosis. Evaluation of intrinsic error. J Bone Joint Surg Am. 1990;72(3):320-7.

64. Torell G, Nachemson A, Haderspeck-Grib K, Schultz A. Standing and supine Cobb measures in girls with idiopathic scoliosis. Spine (Phila Pa 1976). 1985;10(5):425-7.

65. Wessberg P, Danielson BI, Willen J. Comparison of Cobb angles in idiopathic scoliosis on standing radiographs and supine axially loaded MRI. Spine (Phila Pa 1976). 2006;31(26):3039-44.

66. Lee MC, Solomito M, Patel A. Supine magnetic resonance imaging Cobb measurements for idiopathic scoliosis are linearly related to measurements from standing plain radiographs. Spine (Phila Pa 1976). 2013;38(11):E656-61.

67. Lam GC, Hill DL, Le LH, Raso JV, Lou EH. Vertebral rotation measurement: a summary and comparison of common radiographic and CT methods. Scoliosis. 2008;3:16.

68. Drerup B. Principles of measurement of vertebral rotation from frontal projections of the pedicles. J Biomech. 1984;17(12):923-35.

69. Perdriolle R, Vidal J. Thoracic idiopathic scoliosis curve evolution and prognosis. Spine (Phila Pa 1976). 1985;10(9):785-91.

70. Aaro S, Dahlborn M, Svensson L. Estimation of vertebral rotation in structural scoliosis by computer tomography. Acta Radiol Diagn (Stockh). 1978;19(6):9902.

71. Ho EK, Upadhyay SS, Chan FL, Hsu LC, Leong JC. New methods of measuring vertebral rotation from computed tomographic scans. An intraobserver and interobserver study on girls with scoliosis. Spine (Phila Pa 1976). 1993;18(9):1173-7.

72. Adam CJ, Askin GN. Automatic measurement of vertebral rotation in idiopathic scoliosis. Spine (Phila Pa 1976). 2006;31(3):E80-3. 

automatic measurements of axial vertebral rotation for assessment of spinal deformity in idiopathic scoliosis. Phys Med Biol. 2013;58(6):1775-87.

74. Legaye J, Duval-Beaupere G, Hecquet J, Marty C. Pelvic incidence: a fundamental pelvic parameter for three-dimensional regulation of spinal sagittal curves. Eur Spine J. 1998;7(2):99-103.

75. Marty C, Boisaubert B, Descamps H, Montigny JP, Hecquet J, Legaye J, et al. The sagittal anatomy of the sacrum among young adults, infants, and spondylolisthesis patients. Eur Spine J. 2002;11(2):119-25.

76. Roussouly P, Nnadi C. Sagittal plane deformity: an overview of interpretation and management. Eur Spine J. 2010;19(11):1824-36.

77. Cheng JC, Castelein RM, Chu WC, Danielsson AJ, Dobbs MB, Grivas TB, et al. Adolescent idiopathic scoliosis. Nat Rev Dis Primers. 2015;1:15030.

78. Schlosser TPC, Janssen MMA, Hogervorst T, Vrtovec T, de Vos J, Oner FC, et al. The odyssey of sagittal pelvic morphology during human evolution: a perspective on different Hominoidae. Spine J. 2017;17(8):1202-6.

79. King HA, Moe JH, Bradford DS, Winter RB. The selection of fusion levels in thoracic idiopathic scoliosis. J Bone Joint Surg Am. 1983;65(9):1302-13.

80. Cummings RJ, Loveless EA, Campbell J, Samelson S, Mazur JM. Interobserver reliability and intraobserver reproducibility of the system of King et al. for the classification of adolescent idiopathic scoliosis. J Bone Joint Surg Am. 1998;80(8):1107-11.

81. Behensky H, Giesinger K, Ogon M, Krismer M, Hannes B, Karlmeinrad G, et al. Multisurgeon assessment of coronal pattern classification systems for adolescent idiopathic scoliosis: reliability and error analysis. Spine (Phila Pa 1976). 2002;27(7):762-7.

82. Lenke LG, Betz RR, Clements D, Merola A, Haher T, Lowe T, et al. Curve prevalence of a new classification of operative adolescent idiopathic scoliosis: does classification correlate with treatment? Spine (Phila Pa 1976). 2002;27(6):604-11.

83. Lenke LG, Edwards CC, 2nd, Bridwell KH. The Lenke classification of adolescent idiopathic scoliosis: how it organizes curve patterns as a template to perform selective fusions of the spine. Spine (Phila Pa 1976). 2003;28(20):S199207.

84. Ascani E, Bartolozzi P, Logroscino CA, Marchetti PG, Ponte A, Savini R, et al. Natural history of untreated idiopathic scoliosis after skeletal maturity. Spine (Phila Pa 1976). 1986;11(8):784-9. 
85.

86.

87.

88.

89.

90.

91.

92.

93.

94. Cotrel Y, Dubousset J. [A new technic for segmental spinal osteosynthesis using the posterior approach]. Rev Chir Orthop Reparatrice Aappar Mot. 1984;70(6):489-94 [in French].

95. Cotrel Y, Dubousset J, Guillaumat M. New universal instrumentation in spinal surgery. Clin Orthop Relat Res. 1988;227:10-23.

96. Webb JK, Burwell RG, Cole AA, Lieberman I. Posterior instrumentation in scoliosis. Eur Spine J. 1995;4(1):2-5.

97. Hamill CL, Lenke LG, Bridwell KH, Chapman MP, Blanke K, Baldus C. The use of pedicle screw fixation to improve correction in the lumbar spine of patients with idiopathic scoliosis. Is it warranted? Spine (Phila Pa 1976). 1996;21(10):1241-9. 
98. Newton PO, Wenger DR, Mubarak SJ, Meyer RS. Anterior release and fusion in pediatric spinal deformity. A comparison of early outcome and cost of thoracoscopic and open thoracotomy approaches. Spine (Phila Pa 1976). 1997;22(12):1398-406.

99. Sudo H, Ito M, Kaneda K, Shono Y, Abumi K. Long-term outcomes of anterior dual-rod instrumentation for thoracolumbar and lumbar curves in adolescent idiopathic scoliosis: a twelve to twenty-three-year follow-up study. J Bone Joint Surg Am. 2013;95(8):e49.

100. Luque ER. Segmental spinal instrumentation for correction of scoliosis. Clin Orthop Relat Res. 1982(163):192-8.

101. Suk SI, Kim WJ, Lee CS, Lee SM, Kim JH, Chung ER, et al. Indications of proximal thoracic curve fusion in thoracic adolescent idiopathic scoliosis: recognition and treatment of double thoracic curve pattern in adolescent idiopathic scoliosis treated with segmental instrumentation. Spine (Phila $\mathrm{Pa}$ 1976). 2000;25(18):2342-9.

102. Suk SI, Lee CK, Kim WJ, Chung YJ, Park YB. Segmental pedicle screw fixation in the treatment of thoracic idiopathic scoliosis. Spine (Phila Pa 1976). 1995;20(12):1399-405.

103. Dickson RA, Archer IA. Surgical treatment of late-onset idiopathic thoracic scoliosis. The Leeds procedure. J Bone Joint Surg Br. 1987;69(5):709-14.

104. Helenius I, Remes V, Yrjonen T, Ylikoski M, Schlenzka D, Helenius M, et al. Harrington and Cotrel-Dubousset instrumentation in adolescent idiopathic scoliosis. Long-term functional and radiographic outcomes. J Bone Joint Surg Am. 2003;85-a(12):2303-9.

105. Kim YJ, Lenke LG, Cho SK, Bridwell KH, Sides B, Blanke K. Comparative analysis of pedicle screw versus hook instrumentation in posterior spinal fusion of adolescent idiopathic scoliosis. Spine (Phila Pa 1976). 2004;29(18):2040-8.

106. Imrie M, Yaszay B, Bastrom TP, Wenger DR, Newton PO. Adolescent idiopathic scoliosis: should 100\% correction be the goal? J Pediatr Orthop. 2011;31(1 Suppl):S9-13.

107. Abul-Kasim K, Karlsson MK, Ohlin A. Increased rod stiffness improves the degree of deformity correction by segmental pedicle screw fixation in adolescent idiopathic scoliosis. Scoliosis. 2011;6:13.

108. Newton PO, editor. Idiopathic scoliosis: the Harms Study Group treatment guide. Thieme; 2010. p. 165-78.

109. Fang A, Hu SS, Endres N, Bradford DS. Risk factors for infection after spinal surgery. Spine (Phila Pa 1976). 2005;30(12):1460-5. 
110. Fei Q, Li J, Lin J, Li D, Wang B, Meng H, et al. Risk factors for surgical site infection after spinal surgery: a meta-analysis. World Neurosurg. 2016;95:50715.

111. Nota SP, Braun Y, Ring D, Schwab JH. Incidence of surgical site infection after spine surgery: what is the impact of the definition of infection? Clin Orthop Relat Res. 2015;473(5):1612-9.

112. Dwyer AF, Newton NC, Sherwood AA. An anterior approach to scoliosis. A preliminary report. Clin Orthop Relat Res. 1969;62:192-202.

113. Zielke K, Berthet A. [VDS--ventral derotation spondylodesis--preliminary report on 58 cases]. Beitr Orthop Traumatol. 1978;25(2):85-103 [in German].

114. Sudo H, Ito M, Kaneda K, Shono Y, Takahata M, Abumi K. Long-term outcomes of anterior spinal fusion for treating thoracic adolescent idiopathic scoliosis curves: average 15-year follow-up analysis. Spine (Phila Pa 1976). 2013;38(10):819-26.

115. Kaneda K, Shono Y, Satoh S, Abumi K. New anterior instrumentation for the management of thoracolumbar and lumbar scoliosis. Application of the Kaneda two-rod system. Spine (Phila Pa 1976). 1996;21(10):1250-61; discussion 61-2.

116. Anterior spinal fusion - open approach - for idiopathic scoliosis. Aaro Anterior Spine System Surgical Technique. Malmö Sweden: Tresona Instrument AB; 2014.

117. Betz RR, Harms J, Clements DH, 3rd, Lenke LG, Lowe TG, Shufflebarger HL, et al. Comparison of anterior and posterior instrumentation for correction of adolescent thoracic idiopathic scoliosis. Spine (Phila Pa 1976). 1999;24(3):22539.

118. Rhee JM, Bridwell KH, Won DS, Lenke LG, Chotigavanichaya C, Hanson DS. Sagittal plane analysis of adolescent idiopathic scoliosis: the effect of anterior versus posterior instrumentation. Spine (Phila Pa 1976). 2002;27(21):2350-6.

119. Schmidt C, Liljenqvist U, Lerner T, Schulte TL, Bullmann V. Sagittal balance of thoracic lordoscoliosis: anterior dual rod instrumentation versus posterior pedicle screw fixation. Eur Spine J. 2011;20(7):1118-26.

120. Nohara A, Kawakami N, Saito T, Tsuji T, Ohara T, Suzuki Y, et al. Comparison of surgical outcomes between anterior fusion and posterior fusion in patients with AIS Lenke type 1 or 2 that underwent selective thoracic fusion - long-term followup study longer than 10 postoperative years. Spine (Phila Pa 1976). 2015;40(21):1681-9. 
121. Graham EJ, Lenke LG, Lowe TG, Betz RR, Bridwell KH, Kong Y, et al. Prospective pulmonary function evaluation following open thoracotomy for anterior spinal fusion in adolescent idiopathic scoliosis. Spine (Phila Pa 1976). 2000;25(18):2319-25.

122. Kim YJ, Lenke LG, Bridwell KH, Kim KL, Steger-May K. Pulmonary function in adolescent idiopathic scoliosis relative to the surgical procedure. J Bone Joint Surg Am. 2005;87(7):1534-41.

123. Newton PO, Perry A, Bastrom TP, Lenke LG, Betz RR, Clements D, et al. Predictors of change in postoperative pulmonary function in adolescent idiopathic scoliosis: a prospective study of 254 patients. Spine (Phila $\mathrm{Pa}$ 1976). 2007;32(17):1875-82.

124. Kim YJ, Lenke LG, Bridwell KH, Cheh G, Sides B, Whorton J. Prospective pulmonary function comparison of anterior spinal fusion in adolescent idiopathic scoliosis: thoracotomy versus thoracoabdominal approach. Spine (Phila Pa 1976). 2008;33(10):1055-60.

125. Gitelman Y, Lenke LG, Bridwell KH, Auerbach JD, Sides BA. Pulmonary function in adolescent idiopathic scoliosis relative to the surgical procedure: a 10year follow-up analysis. Spine (Phila Pa 1976). 2011;36(20):1665-72.

126. Newton PO, Marks MC, Bastrom TP, Betz R, Clements D, Lonner B, et al. Surgical treatment of Lenke 1 main thoracic idiopathic scoliosis: results of a prospective, multicenter study. Spine (Phila Pa 1976). 2013;38(4):328-38.

127. Cochran T, Irstam L, Nachemson A. Long-term anatomic and functional changes in patients with adolescent idiopathic scoliosis treated by Harrington rod fusion. Spine (Phila Pa 1976). 1983;8(6):576-84.

128. Paonessa KJ, Engler GL. Back pain and disability after Harrington rod fusion to the lumbar spine for scoliosis. Spine (Phila Pa 1976). 1992;17(8 Suppl):S249-53.

129. Moe JH. A critical analysis of methods of fusion for scoliosis; an evaluation in two hundred and sixty-six patients. J Bone Joint Surg Am. 1958;40-a(3):529-54 passim.

130. Dubousset J, Herring JA, Shufflebarger H. The crankshaft phenomenon. J Pediatr Orthop. 1989;9(5):541-50.

131. Crawford CH, 3rd, Lenke LG, Sucato DJ, Richards BS, 3rd, Emans JB, Vitale MG, et al. Selective thoracic fusion in Lenke 1C curves: prevalence and criteria. Spine (Phila Pa 1976). 2013;38(16):1380-5. 
132. Rizkallah M, Sebaaly A, Kharrat K, Kreichati G. Selecting the lowest instrumented vertebra in adolescent idiopathic scoliosis: Comparison of the Lenke, Suk, and Dubousset criteria. Orthop Traumatol Surg Res. 2018;104(5):631-5.

133. Boniello AJ, Hasan S, Yang S, Jalai CM, Worley N, Passias PG. Selective versus nonselective thoracic fusion in Lenke 1C curves: a meta-analysis of baseline characteristics and postoperative outcomes. J Neurosurg Spine. 2015;23(6):72130.

134. Danielsson AJ, Romberg K. Reliability and validity of the Swedish version of the Scoliosis Research Society-22 (SRS-22r) patient questionnaire for idiopathic scoliosis. Spine (Phila Pa 1976). 2013;38(21):1875-84.

135. Stromqvist B, Fritzell P, Hagg O, Jonsson B, Sanden B. Swespine: the Swedish spine register : the 2012 report. Eur Spine J. 2013;22(4):953-74.

136. Ascher M MLS, Burton D, Manna B. The Reliability and Concurrent Validity of the Scoliosis Research Society-22 Patient Questionnaire for Idiopathic Scoliosis. Spine (Phila Pa 1976). 2003;28(1):63-9.

137. Ascher MA LS, Glattes RC, Burton DC, Alanay A, Bago J. Refinement of the SRS-22 Health-Related Quality of Life questionnaire Function domain. Spine (Phila Pa 1976). 2006;31(5):593-7.

138. Rabin R, Charro Fd. EQ-SD: a measure of health status from the EuroQol Group. Ann Med. 2009;33(5):337-43.

139. Devlin NJ, Brooks R. EQ-5D and the EuroQol Group: Past, Present and Future. Appl Health Econ Health Policy. 2017;15(2):127-37.

140. Vrtovec T, Janssen MM, Pernus F, Castelein RM, Viergever MA. Analysis of pelvic incidence from 3-dimensional images of a normal population. Spine (Phila Pa 1976). 2012;37(8):E479-85.

141. Hong JY, Suh SW, Easwar TR, Modi HN, Yang JH, Park JH. Evaluation of the three-dimensional deformities in scoliosis surgery with computed tomography: efficacy and relationship with clinical outcomes. Spine (Phila Pa 1976). 2011;36(19):E1259-65.

142. Stokes IA, Bigalow LC, Moreland MS. Three-dimensional spinal curvature in idiopathic scoliosis. J Orthop Res. 1987;5(1):102-13.

143. Stokes IA, Bigalow LC, Moreland MS. Measurement of axial rotation of vertebrae in scoliosis. Spine (Phila Pa 1976). 1986;11(3):213-8.

144. Farshad M, Catanzaro S, Schmid SL. The spinopelvic geometry in different Lenke curve types of adolescent idiopathic scoliosis. Spine Deform. 2016;4(6):425-31. 
145. Mac-Thiong JM, Labelle H, Charlebois M, Huot MP, de Guise JA. Sagittal plane analysis of the spine and pelvis in adolescent idiopathic scoliosis according to the coronal curve type. Spine (Phila Pa 1976). 2003;28(13):1404-9.

146. Yong Q, Zhen L, Zezhang Z, Bangping Q, Feng Z, Tao W, et al. Comparison of sagittal spinopelvic alignment in Chinese adolescents with and without idiopathic thoracic scoliosis. Spine (Phila Pa 1976). 2012;37(12):E714-20.

147. Clement JL, Geoffray A, Yagoubi F, Chau E, Solla F, Oborocianu I, et al. Relationship between thoracic hypokyphosis, lumbar lordosis and sagittal pelvic parameters in adolescent idiopathic scoliosis. Eur Spine J. 2013;22(11):2414-20.

148. La Maida GA, Zottarelli L, Mineo GV, Misaggi B. Sagittal balance in adolescent idiopathic scoliosis: radiographic study of spino-pelvic compensation after surgery. Eur Spine J. 2013;22 Suppl 6:S859-67.

149. Roussouly P, Labelle H, Rouissi J, Bodin A. Pre- and post-operative sagittal balance in idiopathic scoliosis: a comparison over the ages of two cohorts of 132 adolescents and 52 adults. Eur Spine J. 2013;22 Suppl 2:S203-15.

150. Schlosser TP, Shah SA, Reichard SJ, Rogers K, Vincken KL, Castelein RM. Differences in early sagittal plane alignment between thoracic and lumbar adolescent idiopathic scoliosis. Spine J. 2014;14(2):282-90.

151. Pasha S, Aubin CE, Sangole AP, Labelle H, Parent S, Mac-Thiong JM. Threedimensional spinopelvic relative alignment in adolescent idiopathic scoliosis. Spine (Phila Pa 1976). 2014;39(7):564-70.

152. Schlosser TP, Vincken KL, Rogers K, Castelein RM, Shah SA. Natural sagittal spino-pelvic alignment in boys and girls before, at and after the adolescent growth spurt. Eur Spine J. 2015;24(6):1158-67.

153. Upasani VV, Tis J, Bastrom T, Pawelek J, Marks M, Lonner B, et al. Analysis of sagittal alignment in thoracic and thoracolumbar curves in adolescent idiopathic scoliosis: how do these two curve types differ? Spine (Phila Pa 1976). 2007;32(12):1355-9.

154. Schlosser TP, Janssen MM, Vrtovec T, Pernus F, Oner FC, Viergever MA, et al. Evolution of the ischio-iliac lordosis during natural growth and its relation with the pelvic incidence. Eur Spine J. 2014;23(7):1433-41.

155. Vrtovec T, Janssen MM, Likar B, Castelein RM, Viergever MA, Pernus F. Evaluation of pelvic morphology in the sagittal plane. Spine J. 2013;13(11):15009 .

156. Philippot R, Wegrzyn J, Farizon F, Fessy MH. Pelvic balance in sagittal and Lewinnek reference planes in the standing, supine and sitting positions. Orthop Traumatol Surg Res. 2009;95(1):70-6. 
157. Sucato DJ, Agrawal S, O'Brien MF, Lowe TG, Richards SB, Lenke L. Restoration of thoracic kyphosis after operative treatment of adolescent idiopathic scoliosis: a multicenter comparison of three surgical approaches. Spine (Phila Pa 1976). 2008;33(24):2630-6. 


\section{Papers}

The papers associated with this thesis have been removed for copyright reasons. For more details about these see:

http://urn.kb.se/resolve?urn=urn:nbn:se:liu:diva-152572 